\title{
HARNESSING THE FULL POTENTIAL OF CORONERS' RECOMMENDATIONS
}

\author{
Elena Mok*
}

The ability of coroners to make recommendations to various agencies and organisations is inextricably linked with the coroner's emerging role in death and injury prevention. Despite this, there is no legal obligation in New Zealand for agencies and organisations to respond to, or implement, proposed changes, which has led to claims that recommendations are being overlooked. However, concerns have also been raised about the quality of some recommendations, especially whether coroners have sufficient expertise to be proposing wide-ranging legal and policy reforms. This article analyses the extent to which recommendations are being implemented by the agencies and organisations to whom they are directed, and addresses whether the criticisms levelled at recommendations are valid. It is contended that greater transparency and accountability is needed in coronial processes to fully harness the preventive and therapeutic potential of coroners' recommendations.

\section{INTRODUCTION}

The primary role of coroners is to establish the cause and circumstances of sudden or unexplained deaths and deaths in other special circumstances. ${ }^{1}$ Unlike other investigations into accidents and deaths, coronial investigations focus on the person who has died and the circumstances of their death. This provides clarity for the deceased's family and assures the community that no death will be "overlooked, concealed or ignored". ${ }^{2}$

Despite this, a separate and wider function, "the prevention of death by the public exposure of conditions that threaten life", has become increasingly significant and, in some cases, just as crucial as the investigation of the facts surrounding individual deaths. ${ }^{3}$ The coroner's ability to make

\footnotetext{
* Submitted as part of the LLB (Hons) programme at Victoria University of Wellington. The author would like to thank Professor Bill Atkin for his valuable supervision and feedback, as well as Steven Li and Caitlin Craigie for their editing assistance.

1 Coroners Act 2006, s 4(2).

2 People First of Ontario v Porter (1991) 5 OR (3d) 609 (Ontario Court (General Division)) at [57].

3 At [33].
} 
recommendations to government agencies and other organisations for the purpose of preventing deaths in similar circumstances is inextricably linked with this role. However, the extent to which recommendations contribute to positive health and safety outcomes is uncertain. Further, concerns have been raised, both in New Zealand and overseas, regarding the quality of recommendations, the sources of expertise coroners draw on and the lack of involvement of key parties before recommendations are released. ${ }^{4}$ As a result, the Minister for Courts has proposed various amendments to the Coroners Act 2006 (the Act) following a Ministry of Justice review (MOJ review). The coroner's recommendation-making power will be the most significant area of reform. ${ }^{5}$

This article addresses the issues surrounding coroners' recommendations and discusses whether reform in this area is necessary. Part II provides an overview of the coroner's role in death and injury prevention. Part III discusses a small-scale study undertaken for the purposes of this article to examine the nature and frequency of coroners' recommendations in New Zealand, as well as the factors which prompt agencies and organisations to implement recommendations. Part IV examines whether the criticisms levelled at recommendations are valid. Finally, Part V proposes various reforms that, if implemented, would enhance the preventive and therapeutic potential of the coronial process.

\section{THE CORONER'S ROLE IN DEATH PREVENTION}

One of the most enduring features of the coronial process has been its ability to evolve in response to community needs. ${ }^{6}$ Early New Zealand coronial practice was largely modelled on the English system, ${ }^{7}$ and was intimately connected with the criminal law. ${ }^{8}$ If a coroner's jury delivered a verdict of murder or manslaughter against a person, this had the effect of an indictment: the coroner was obliged to issue a warrant for the apprehension of the accused and commit him or her to prison. ${ }^{9}$ However, the establishment of a police force rendered this function redundant, ${ }^{10}$ and the

4 Cabinet Paper "Coroners Act Review: Proposals for Reform - Paper 1" (Ministry of Justice, 26 June 2013) at $[5]$.

5 At [5]. At the time of publication, the Coroners Amendment Bill 2014 (239-1) had just been placed before the House of Representatives. The Bill incorporates the reforms proposed by the Ministry of Justice in its targeted review concerning the coroner's recommendation-making power. See specifically cl 30, which inserts two new provisions: ss 57A and 57B.

6 Ian Freckelton and David Ranson Death Investigation and the Coroner's Inquest (Oxford University Press, Melbourne, 2006) at 752.

7 Freckelton and Ranson, above n 6, at 28. The coronial system was introduced into New Zealand under the Coroners Ordinance 1846.

8 Luce Committee Death Certification and Investigation in England, Wales and Northern Ireland, Report of a Fundamental Review (HMSO, Cm 5831, 2003) at 87.

$9 \quad$ Freckelton and Ranson, above n 6, at 30.

10 At 30 . 
Criminal Code Act 1893 explicitly stated that no person should be tried on a coroner's inquisition. ${ }^{11}$ Juries were eventually abolished in $1951 .^{12}$

The coroner's inquest subsequently developed into an inquisitorial fact-finding exercise, rather than a method of apportioning guilt. ${ }^{13}$ Coroners are now expressly precluded from determining any kind of liability. ${ }^{14}$ With the exclusion of coroners "from anything resonant of criminal adjudication", ${ }^{15}$ and the proliferation of public bodies with death investigation functions, it became increasingly apparent that coronial investigations needed to be able to go beyond cause of death if they were to serve a "useful social function". ${ }^{16}$ The erosion of the coroner's traditional role even caused some to question whether coroners had become an "anachronism worth retaining". ${ }^{17}$

Recognition that the coroner's role needed revitalising coincided with the public health movement in the 1980s, which focused on the relationship between social and environmental factors in health, "with the aim of managing problems identified as posing a health threat to the community". ${ }^{18}$ Public health research showed that proper appraisal of supposedly insignificant incidents could reveal, and subsequently remove or mitigate, the risk of future deaths. ${ }^{19}$ Every death represented the "tip of an iceberg of injuries", ${ }^{20}$ so when patterns of injury surfaced, this was indicative of a collective public health problem. ${ }^{21}$ Accordingly, a broad-based multi-disciplinary strategy not only has the potential to forestall deaths, but to alleviate health and safety risks more generally. ${ }^{22}$ An effective preventive strategy requires an understanding of the way an entire system

11 See also Coroners Act 1908, s 6.

12 Coroners Act 1951, s 13(1).

13 Law Commission Coroners (NZLC R62, 2000) at [6].

14 Coroners Act 2006, s 57(1).

15 Freckelton and Ranson, above n 6, at 716.

16 Orchard v Osborne \& Anor HC Auckland M101-96, 19 July 1996 at 7 per Paterson J.

17 Freckelton and Ranson, above n 6, at 714

18 At 719 .

19 Law Commission, above n 13, at [10].

20 Boronia Halstead "Coroners' recommendations following deaths in custody" in Hugh Selby (ed) The Inquest Handbook (Federation Press, New South Wales, 1998) 186 at 187.

21 James Harrison and Jerry Moller "Learning from experience: towards prevention" in Hugh Selby (ed) The Inquest Handbook (Federation Press, New South Wales, 1998) 208 at 208.

22 Halstead, above n 20, at 187. 
of influences operates, as attributing responsibility to one part of the system is ineffective in solving systemic problems. ${ }^{23}$

Deaths without known cause, suicides, unnatural or violent deaths, and deaths that occurred during medical operations or in official custody or care must all be reported to the coroner. ${ }^{24}$ The wide variety of deaths that come within coroners' purview means they are well placed to acquire a pattern-informed viewpoint of issues concerning death and injury. ${ }^{25}$ The coroner's role in preventing death and injury has the ability to give the coronial process a new sense of relevance, ${ }^{26}$ and this aspect of the coroner's inquiry has consequently become a prominent feature in the evolution of the coronial process in New Zealand, culminating in its express recognition in s 4(2)(b) of the Act. This provision allows coroners to make recommendations to reduce the likelihood of deaths in similar circumstances. Recommendations are the principal mechanism by which coroners can address death and injury prevention. ${ }^{27}$ By attempting to persuade agencies and organisations to implement changes designed to protect the community, the coroner's focus "transcends the criminal and broadly embraces the prophylactic". ${ }^{28}$ Coroners can therefore be reasonably regarded as part of the state's public health apparatus. ${ }^{29}$

\section{CURRENT IMPLEMENTATION OF RECOMMENDATIONS}

\section{A Enforceability of Recommendations and Factors Influencing Implementation}

In New Zealand, individuals, organisations or agencies to whom coroners' recommendations are directed are not legally required to respond to, or implement, proposed changes. ${ }^{30}$ As coroners have no formal powers to command attention, agencies and organisations that elect to ignore recommendations theoretically can do so with "impunity and without scrutiny". ${ }^{31}$ However, coroners' decisions frequently generate considerable publicity. ${ }^{32}$ This can be a powerful catalyst for

23 Harrison and Moller, above n 21, at 220.

24 Coroners Act 2006, s 13.

25 Freckelton and Ranson, above n 6, at 719.

26 At 756.

27 At 714 .

28 Ian Freckelton "Death Investigation and the Evolving Role of the Coroner" (2008) 11 Otago LR 565 at 583.

29 Freckelton and Ranson, above n 6, at 719.

30 Lyndal Bugeja and David Ranson "Coroners' Recommendations: A Lost Opportunity" (2005) 13 JLM 173 at 174.

31 Halstead, above n 20, at 186.

32 Freckelton and Ranson, above n 6, at 616. 
promoting change, ${ }^{33}$ as it forces agencies that are subject to recommendations to defend their response at the bar of public opinion. ${ }^{34}$ That said, media coverage is contingent on the degree of public interest in the incident. Where there is delay between the death and the inquest, the "topicality" of the material is seriously diminished. ${ }^{35}$ Thus, while media attention can expedite the implementation of recommendations, if one accepts the importance of recommendations, then the current regime is plainly inadequate and fails to fulfil the public interest in death prevention. ${ }^{36}$

Although they are regularly asserted to be the most influential element of coroners' findings, overseas research suggests that recommendations are rarely implemented. ${ }^{37}$ An Australian study completed in 2006 concluded that multiple factors affect implementation, including whether: ${ }^{38}$

- the recommendation is feasible;

- implementation accords with government policies and priorities;

- a system for reviewing recommendations exists within the relevant organisation;

- coronial recommendations arising out of similar deaths are drawn to the attention of relevant authorities;

- the inquest and its recommendations attract media attention; and

- public advocacy accompanies the recommendation.

In New Zealand, coroners and families have publicly expressed concern on numerous occasions that recommendations are being ignored. ${ }^{39}$ Yet in the absence of any official reporting system for coroners' decisions, accurately determining how frequently coroners make recommendations and the extent to which recommendations are implemented, is difficult. For the purposes of this article, a small-scale study was undertaken to ascertain whether agencies and organisations were in fact failing to act upon recommendations. The methodology and findings of this study are discussed below.

33 Jack Waterford "The media and inquests" in Hugh Selby (ed) The Inquest Handbook (Federation Press, New South Wales, 1998) 52 at 64.

34 Innis MacLeod "The Ombudsman" (1966) 19 Admin L Rev 93 at 94.

35 Waterford, above $\mathrm{n} 33$, at 54.

36 Halstead, above n 20, at 186; Freckelton, above n 28, at 581.

37 Freckelton and Ranson, above n 6, at 738.

38 Law Reform Commission of Western Australia Review of Coronial Practice in Western Australia: Discussion Paper (June 2011) at 168-169.

39 See generally Mike Watson "Plea not to let coroners' rulings wither" (22 March 2013) Stuff.co.nz <www.stuff.co.nz>; Joanne Carroll "Official road improvement ideas get lost or ignored" The New Zealand Herald (online ed, New Zealand, 19 February 2012); Lane Nichols "Key Kahui recommendation ignored in new abuse paper" The New Zealand Herald (online ed, New Zealand, 11 October 2012); "Coronial recommendations 'die in ditch' - judge" (13 May 2012) TVNZ <www.tvnz.co.nz〉. 


\section{B Research Methodology}

One hundred findings from between April 2012 to January 2013, as well as 24 findings of public interest, were selected for analysis. ${ }^{40}$ Various public agencies and private organisations were contacted and asked to provide information about whether they had received and implemented specific coroners' recommendations and, if not, to provide reasons why those recommendations had not been acted upon.

Except where recommendations were targeted at private organisations, information and supporting documentation was obtained under the Official Information Act 1982 (OIA) ${ }^{41}$ In 13 cases, coroners recommended that their findings be forwarded to public health agencies solely for data collection purposes. As such, these recommendations were not included when assessing the extent of substantive implementation.

\section{Results of Study}

In total, 154 formal recommendations were made across 79 of the cases examined. ${ }^{42}$ The nature of recommendations varied significantly across cases. Some recommendations targeted specific issues, such as the installation of road signage, ${ }^{43}$ the removal of trees along railway tracks ${ }^{44}$ and a review of street lighting in a particular area. ${ }^{45}$ Others suggested broad-ranging education campaigns, ${ }^{46}$ and legal and policy changes, including an investigation of the range of charges

40 See Ministry of Justice "Coronial findings of public interest" <www.justice.govt.nz>.

41 Several of the organisations contacted did not respond to requests for information, and one OIA request was rejected. See Letter from Barry Taylor (National Manager of Operations, Police National Headquarters) to Elena Mok regarding implementation of coroners' recommendations by Police (3 September 2013).

42 See Appendix One, Tables 5 and 6.

43 In the matter of an inquiry into the death of Geoffrey William Druce NZCorC Hamilton CSU-2011-HAM000568, 30 August 2012; In the matter of an inquiry into the death of Gene Robert Charles Stantiall NZCorC Hamilton CSU-2011-HAM-000624, 16 May 2012; In the matter of an inquiry into the death of Pauline Winifred Wilson NZCorC Auckland CSU-2010-CCH-000477, 22 May 2012.

44 In the matter of an inquiry into the death of Rosalyn Sylvia Yong NZCorC Palmerston North CSU-2011PNO-000519, 27 July 2012.

45 In the matter of an inquest into the death of Norman Bruce Thompson NZCorC Oamaru CSU-2010-DUN000210,13 January 2012.

46 See for instance In the matter of an inquest into the death of Alexis Green, an infant NZCorC Christchurch CSU-2011-CCH-000961, 7 September 2012; In the matter of an inquiry into the death of Amanda Sharon Brunt NZCorC Hamilton CSU-2011-HAM-000244, 30 July 2012; In the matter of an inquiry into the death of Blair Calvin Edwards NZCorC Christchurch CSU-2010-CCH-000609, 23 November 2012; In the matter of an inquiry into the death of Geoffrey Raymond Gill NZCorC Invercargill CSU-2011-DUN-000400, 3 August 2012. See also Appendix One, Table 8. 
available in hunting accidents, ${ }^{47}$ warning labels on alcohol ${ }^{48}$ and caffeinated beverages, ${ }^{49}$ and for district health boards (DHBs) to develop information sharing protocols for families following incidents in patient mental health care. ${ }^{50}$ Even where no formal recommendations were made, the coroner would usually make comments warning affected sections of the public to take care in similar circumstances. ${ }^{51}$

The level of input participants offered in the formulation of recommendations also varied. Agencies and organisations sometimes offered suggestions for internal changes that they believed would help prevent further deaths, usually where an internal review or other investigation had already been conducted. ${ }^{52}$ Where an internal review or other investigation had resulted in recommendations, but these had not yet been fully implemented, the coroner would often endorse and adopt these proposals when making recommendations. ${ }^{53}$ Recommendations were also occasionally suggested by experts assisting the coroner or by the deceased's family, either personally or through counsel. ${ }^{54}$

Altogether, 57.14 per cent of recommendations had been substantively implemented by the relevant agency or organisation, and 16.88 per cent had either been partially implemented or were scheduled for further consultation. ${ }^{55}$ Most agencies gave consideration to recommendations and offered a response. Recommendations to the Department of Corrections and the Ministries of Health and Social Development, particularly in cases involving sudden unexpected death in infancy (SUDI) or sudden infant death syndrome (SIDS), had a high rate of substantive implementation. ${ }^{56}$

47 In the matter of an inquest into the death of James Wilson Dodds NZCorC Rotorua CSU-2012-ROT000308, 18 March 2013.

48 In the matter of an inquiry into the death of Megan Anne Uren NZCorC Christchurch CSU-2011-CCH000967, 22 January 2013.

49 In the matter of an inquiry into the death of Natasha Marie Harris NZCorC Invercargill CSU-2010-DUN000069, 11 February 2013.

50 In the matter of an inquiry into death of $M r R$ NZCorC Palmerston North CSU-2012-PNO-000151, 4 January 2013.

51 See Appendix One, Table 5. See for instance In the matter of an inquiry into the death of Jack Maynard Wiki NZCorC Whangarei CSU-2009-WHG-000270, 12 February 2013. Here, the deceased drowned while trying to rescue his grandchildren from a rip. Although Coroner Shortland declined to make any formal recommendations, he observed that the circumstances of the case served as a reminder to all New Zealanders to never underestimate sea conditions and to be alert to how quickly conditions can change.

52 See Appendix One, Tables 9 and 10.

53 See Appendix One, Table 9.

54 See Appendix One, Table 9.

55 See Appendix One, Table 7.

56 See Appendix One, Chart 2. 
Recommendations aimed at more limited changes, such as signage alterations or the development of specific protocols, were often quickly implemented following the coroner's inquiry. ${ }^{57}$ Recommendations relating to public education also received high levels of support, generally because agencies already had campaigns in place prior to the inquiry. ${ }^{58}$ In contrast, recommendations relating to wide-ranging regulatory or legal changes tended to receive standardised responses, with little or no prospect of implementation. ${ }^{59}$ It was evident from many responses that some recommendations could not feasibly be implemented, even though the intention behind the recommendation may have been supported.

In several cases, implementation had not occurred because recommendations had not been communicated to the proper agency or organisation, or had been lost in the bureaucratic process. ${ }^{60}$ Alternatively, the recommendations had been forwarded to an agency with no power to make the suggested changes. ${ }^{61}$ These issues are unsurprising for several reasons. First, agencies have different processes in place for recording coroners' findings and recommendations where they have been an "interested party" in the inquiry. Secondly, there is no specific referral process for recommendations: it is up to each individual coroner to decide where to send the recommendations. ${ }^{62}$ Further, although Coronial Services maintains a list stating that certain agencies are to receive specific types of recommendations, Coronial Services does not follow up on

57 See Appendix One, Chart 1.

58 See Appendix One, Chart 1.

59 See Appendix One, Chart 1.

60 See Appendix One, Table 7.

61 For instance, the Minister of Consumer Affairs had no ability to set up a licensing regime to regulate the hire of stud and bolt guns, as recommended by Coroner Smith following the William McLay inquiry. See Letter from Simon Bridges (Former Minister of Consumer Affairs) to Ian Smith (Wellington Regional Coroner) regarding the Coroner's recommendations following the death of William Stuart Dalzel McLay (2 August 2012) (Obtained under Official Information Act 1982 Request to Ministry of Business, Innovation and Employment).

62 Letter from Dean Skachill (Business Services Manager of Specialist Courts, Ministry of Justice) to Elena Mok regarding referral processes in place for notifying interested parties about coroners' recommendations (31 July 2013) at 1 . In the course of the study, this meant that it was sometimes unclear which agency or organisation was the subject of the coroner's recommendations, particularly in transport-related deaths. See for instance In the matter of an inquiry into the death of Amanda Sharon Brunt NZCorC Hamilton CSU2011-HAM-000244, 30 July 2012; In the matter of an inquiry into the death of Geoffrey William Druce, above $\mathrm{n} 43$; In the matter of an inquiry into the death of Ashley Bruce Foley NZCorC Hamilton CSU-2012HAM-000319, 23 January 2013; In the matter of an inquiry into the death of Shaun Karl Malthus NZCorC Hamilton CSU-2011-HAM-000321, 30 April 2012; In the matter of an inquiry into the death of Richard Warren Toneycliffe NZCorC Palmerston North CSU-2012-PNO-000209, 7 March 2013. In all of these cases, recommendations were simply directed to the "relevant roading authority". 
whether recommendations have been responded to, let alone received, by that agency or organisation. ${ }^{63}$

Overall, each of the factors identified in the Australian study appear to have influenced whether the recommendations examined as part of this article were implemented. Despite claims that recommendations are being ignored, the results of the study suggest that most recommendations will receive at least some consideration. This accords with the preliminary findings of a more comprehensive study by the University of Otago. ${ }^{64}$ Nevertheless, improvements could be made to the coronial process to ensure that recommendations are consistently contributing to positive health and safety outcomes. The following Part assesses the validity of criticisms levelled at recommendations in greater depth in order to determine whether modifications should be made to the coroner's recommendation-making power.

\section{ISSUES SURROUNDING CORONERS' RECOMMENDATIONS}

\section{A Impractical and Wide-Ranging Recommendations}

\section{Costly and impractical recommendations}

Recommendations can be profoundly important in highlighting dangerous practices, policies and products, but they can also be expensive and problematic to implement. ${ }^{65}$ These recommendations are less likely to receive consideration and be acted on by the relevant agency. ${ }^{66}$ In the Debbie Ashton case, the deceased died in a car crash caused by another driver, Jonathan Barclay, who was intoxicated and driving while disqualified. ${ }^{67}$ One of the key issues at the inquest was how Barclay had come to be driving on a public road when he had been disqualified several weeks earlier. ${ }^{6}$ Coroner Evans recommended that the Ministry of Transport (MOT) consider amending the Land Transport Act 1998 to clarify that, in cases where a person is disqualified from

63 Letter from Dean Skachill to Elena Mok, above n 62, at 1.

64 See Jennifer Moore "Coroners' recommendations about healthcare-related deaths as a potential tool for improving patient safety and quality of care" (2014) 127 NZMJ 35. See also Georgina Stylianou "Research into coroners' recommendations" (15 May 2012) Stuff.co.nz <www.stuff.co.nz>; University of Otago "Otago law researchers suggest changes to improve Coroners' recommendations" (press release, 5 August 2013).

65 Ian Freckelton "Inquest Law" in Hugh Selby (ed) The Inquest Handbook (Federation Press, New South Wales, 1998) 1 at 7.

66 See Appendix One, Chart 1.

67 In the matter of an inquest into the death of Debbie Marie Ashton NZCorC Wellington CSU-2006-WGN000000, 19 December 2012.

68 At [12]. 
driving and sentenced to imprisonment, the disqualification order should not take effect until the date on which the person is released from prison, unless the Court decides otherwise. ${ }^{69}$

Officials later raised several operational and policy concerns with the recommendation. ${ }^{70}$ First, implementing the recommendation would have required an information transfer system between the Department of Corrections and the New Zealand Transport Agency concerning release dates for prisoners with driving disqualifications. ${ }^{71}$ The cost of creating such a system (not including maintenance costs) was estimated to be approximately $\$ 300,000$ to $\$ 400,000$. ${ }^{72}$ Secondly, developing such a system was largely unnecessary: although disqualification orders usually commence from the date of sentencing, ${ }^{73}$ judges already had discretion to give effect to the Coroner's concern in appropriate cases by simply ordering a term of disqualification for longer than the term of imprisonment imposed. ${ }^{74}$ As noted in the MOT's response to the Coroner, this practice had in fact been applied in around 60 per cent of cases in which an offender had been disqualified and imprisoned. ${ }^{75}$ Finally, as demonstrated by the circumstances of the Ashton case, disqualification does not actually prevent individuals from driving illegally. Accordingly, adopting the recommendation would not necessarily have improved public safety in any meaningful way. ${ }^{76}$

Impractical and costly recommendations not only diminish public confidence in the coronial system and subject coroners to accusations of "amateur do-goodism", but also detract from the force of well-founded recommendations. ${ }^{77}$ For instance, a number of recommendations were made following an inquest into the death of Stephen Fitzgerald, who was struck by a truck while cycling. ${ }^{78}$ One of the Coroner's recommendations to the MOT - that all cyclists be required to wear

69 At [55].

70 Dawn Kerrison and Leo S Mortimer Response to Coroner's Recommendation in Relation to the Death of Debbie Marie Ashton (Ministry of Transport, Briefing Paper OC01467, 5 April 2013) at [6] (Obtained under Official Information Act 1982 Request to the Ministry of Transport).

71 At [31].

72 At [35].

73 At [14].

74 At [37].

75 At [7].

76 Letter from Gerry Brownlee (Minister of Transport) to Garry Evans (Coroner for Wellington region) regarding recommendations made following Debbie Marie Ashton inquest (11 April 2013) at 3 (Obtained under Official Information Act 1982 Request to Ministry of Transport).

77 Freckelton and Ranson, above n 6, at 737-738. See further David Farrar "Coroner recommendations" (18 February 2013) Kiwiblog <www.kiwiblog.co.nz>; David Farrar Another daft Coroner recommendation (15 February 2013) Kiwiblog <www.kiwiblog.co.nz>.

78 In the matter of an inquest into the death of Stephen Fitzgerald NZCorC Wellington CSU-2008-WGN000310, 31 January 2013. 
high-visibility clothing while cycling on public roads - was met with considerable opposition from officials, cycling groups and the public, ${ }^{79}$ despite the Coroner's belief that such a measure was a "no-brainer". ${ }^{80}$ The media made much of the fact that the deceased had been wearing reflective stripes and that his lights were working at the time of the accident. ${ }^{81}$ The MOT consequently declined to adopt the recommendation on the basis that legal regulation in this area was undesirable and would deter many New Zealanders from cycling. ${ }^{82}$ Nevertheless, several of the Coroner's lesspublicised suggestions were quickly acted upon by the local council, including a further review of the accident site. ${ }^{83}$

\section{Link between findings and recommendations}

Recommendations are vulnerable to criticism where they appear to go beyond the circumstances of the case and evidence before the coroner. ${ }^{84}$ An illustration of this is the case of Natasha Harris, who died from cardiac arrhythmia after consuming around ten litres of Coke per day for many years. ${ }^{85}$ Although Coroner Crerar noted that many ingredients of Coke could be labelled as addictive, he concluded that the Coca Cola Company could not be held responsible for the health of consumers who ingested unhealthy quantities of the product. ${ }^{86}$ However, he recommended that Coca Cola and the Ministry of Health $(\mathrm{MOH})$ consider placing warning labels on soft drinks to inform consumers of the health risks associated with consuming excessive quantities of such products. ${ }^{87}$ This suggestion received criticism from both the public and industry specialists, with New Zealand Food \& Grocery Council Chief Executive Katherine Rich stating that, "there isn't a

79 Henry Peach and Leo S Mortimer Response to Coroner Ian Smith's Recommendations on Cycle Safety Questions and answers to support Minister Woodhouse's response to Coroner Ian Smith (Ministry of Transport, Briefing Paper OC01501, 15 March 2012) at 1 (Obtained under Official Information Act 1982 Request to the Ministry of Transport).

80 In the matter of an inquest into the death of Stephen Fitzgerald, above n 78, at [35].

81 In the matter of an inquest into the death of Stephen Fitzgerald, above n 78, at [11]; Farrar "Coroner recommendations", above n 77; Hilleke "Another 'no brainer' Coroner's report (February 2013) Cycling in Wellington <www.cyclingwellington.co.nz>; "Cycling group opposes mandatory high-visibility clothing" (15 February 2013) Radio New Zealand News <www.radionz.co.nz〉.

82 Peach and Mortimer, above n 79. The Ministry supported the intent of the recommendation but preferred public education to legal regulation or increased enforcement.

83 Letter from Tony Stallinger (Chief Executive of Hutt City Council) to Catherine Langman (Coronial Services Unit) regarding the Coroner's recommendation to Hutt City Council following the death of Stephen Fitzgerald (25 February 2013) (Obtained under Official Information Act 1982 Request to Hutt City Council). Work on the relevant interchange is scheduled for the end of 2013.

84 Cabinet Paper, above n 4, at [20.1].

85 An inquiry into the death of Natasha Marie Harris, above n 49.

86 At [71]

87 At [85]-[88]. 
labelling regime in the world" that could have prevented the death of someone who chose to drink Coke in such large quantities. ${ }^{88}$

Similar recommendations were made in the case of Megan Uren, who died of an acute subdural haemorrhage after a fall. ${ }^{89}$ The Coroner concluded that the death was attributable to the amount of alcohol the deceased had consumed and recommended that all alcoholic beverages should display warnings that excessive consumption may be fatal. ${ }^{90}$ Although the Coroner was fairly of the view that "makers of products containing an inherently dangerous substance have an ethical obligation to warn consumers of its dangers", there was no evidence that warning labels would have prevented the death in question, especially given the deceased had been diagnosed with alcoholism prior to her death. ${ }^{91}$ While it is plausible the deceased may not have developed alcoholism had she been informed of the dangers of excessive alcohol consumption, no explanation of this kind was offered in the Coroner's finding.

However, there are also examples of coroners exercising restraint and confining their inquiries to the circumstances of the particular death in question. In the Jason Palmer inquest, the deceased, a Corrections Officer, was punched in the head by a prisoner and killed after striking his head on a concrete walkway. ${ }^{92}$ In exploring the possible systemic failures contributing to the death, Coroner Matenga emphasised that: ${ }^{93}$

The circumstances of this case must be kept in mind and it is not in my view, an appropriate case to make such wide ranging recommendations on the housing and management of reclassified prisoners into specific units.

A similar approach was taken in the Elizabeth Gilbertson inquiry, where the deceased died of cardiac arrhythmia during an evidential breath test. ${ }^{94}$ At the inquest, the Clinical Director of the Forensic Pathology Service and the deceased's brother suggested several improvements the Police could make to prevent similar deaths, including carrying an emergency defibrillator and utilising

88 Nick Perry "2-gallon a day cola habit linked to woman's death" NBC News (online ed, New York City, 13 February 2013); Andres Jauregui "Soft Drink Warning Labels Face Criticism After Coroner's Finding On Natasha Harris' Coca-Cola Habit" Huffington Post (online ed, New York City, 19 February 2013). See also David Farrar "Coroner recommendations", above n 77.

89 In the matter of an inquiry into the death of Megan Anne Uren, above n 48.

90 At 2 .

91 At 2.

92 In the matter of an inquest into the death of Jason Clint Martin Palmer NZCorC Auckland CSU-2010AUK-000619, 22 August 2012 at [1].

93 At [26].

94 In the matter of an inquiry into the death of Elizabeth Jill Gilbertson NZCorC Hamilton CSU-2012-HAM000275, 27 March 2013 at [21]. 
CCTV on traffic alcohol buses. ${ }^{95}$ Although the Coroner considered these suggestions to be sensible and commended them to the Police, he considered it inappropriate to make formal recommendations. ${ }^{96}$ While CCTV would have been helpful to the Police in such inquiries, it would not have assisted in the prevention of similar deaths. Likewise, there was no evidence that earlier use of a defibrillator would have made any difference in this case.

\section{More than one accepted practice}

Recommendations are also likely to be misguided in circumstances where there is more than one accepted industry practice. In particular areas of medical practice, there may be genuine disagreement as to methods of best practice, and doctors will often differ as to the ideal or even acceptable practice in some cases. ${ }^{97}$ Submitters to the MOJ review also questioned the approach undertaken by coroners to ensure that recognised industry experts are consulted. ${ }^{98}$

If coroners only obtain advice from one practitioner at inquests, coroners may remain oblivious to differences of opinion within that field. ${ }^{99}$ Practitioners who hold an accepted alternative view may consequently regard any recommendations with disdain. ${ }^{100}$ In the Adam Barlow inquest, it was ruled that death had resulted from intrapartum asphyxia after the mother's lead maternity carer failed to communicate any urgency to the hospital midwives regarding the labour. ${ }^{101}$ The New Zealand College of Midwives expressed concern about several of Coroner Matenga's recommendations regarding the regulation of midwifery services and emphasised that there was a lack of consensus between maternity hospital policies around the world. ${ }^{102}$

\section{B Implicit Apportionment of Blame}

Recommendations can have considerable financial and reputational consequences for those affected. ${ }^{103}$ This is because it is difficult, if not impossible, for coroners to recommend preventive

\footnotetext{
95 At [18] and [20].

96 At [21].

97 Freckelton and Ranson, above n 6, at 738.

98 Cabinet Paper, above n 4, at [20.4].

99 Freckelton and Ranson, above n 6, at 738.
}

100 At 738 .

101 In the matter of an inquest into the death of Adam Barlow NZCorC Hamilton CSU-2010-HAM-000021, 7 May 2012 at [85].

102 Office of the Chief Coroner of New Zealand Recommendations Recap - Issue 3 (Ministry of Justice, March 2013) at 17.

103 Freckelton and Ranson, above n 6, at 616. See also Matthews v Hunter [1993] 2 NZLR 683 (HC) at 687 per Heron J. 
measures without first concluding that the death in question was preventable. ${ }^{104}$ As a result, the making of recommendations, particularly in relation to individuals such as health professionals, may imply blame in a manner that is not conducive to a therapeutic, collaborative process. This is exacerbated by the inquisitorial nature of coronial inquiries, which enables coroners to admit any evidence regardless of whether it would be admissible in court, ${ }^{105}$ and the fact that participants often have "fundamentally and adversarially opposed objectives". ${ }^{106}$ While families may wish to use the coronial process to hold individuals and organisations to account and to facilitate secondary legal proceedings, individuals and agencies often seek to minimise their connection to the death and to persuade the coroner not to make recommendations so as to avoid negative publicity after the inquiry. ${ }^{107}$ This can result in disputes concerning issues of blame for past events instead of a focus on measures that could prevent deaths in similar circumstances. ${ }^{108}$

The issue of implicit blame was addressed in Berryman $v$ Solicitor-General, where Mallon J noted that: 109

... in identifying the cause and circumstances of the death, and making comments or recommendations so that lessons may be learnt, it is sometimes inevitable that fault is attributed to a party. This is not fault in the legal sense that legal consequences will follow - the findings at an inquest are not conclusive and may be traversed in other proceedings.

Thus, while coroners should exercise caution to avoid the implicit allocation of blame wherever possible, in circumstances where this is necessary to explain how the death occurred, then such a comment or finding is permissible. ${ }^{110}$ The coroner's search for the "truth" is arguably better served by an inquisitorial jurisdiction, as a "strict application of the adversarial rules of evidence and procedures would severely curtail this role and unduly hamstring a coronial inquiry, effectively

104 Victoria Law Reform Committee Review of the Coroners Act 1985 (Parliamentary Paper No 229 of Session 2003-2006, 14 September 2006) at 383.

105 Coroners Act 2006, s 79(1). The wide-ranging investigative powers granted to coroners under the Act, such as the power to summon and cross-examine witnesses under ss 117(3)(a) and 88(b) respectively, are also consistent with an inquisitorial jurisdiction.

106 Freckelton, above n 65, at 3.

107 At 7 .

108 Victoria Law Reform Committee, above n 104, at 382-383.

109 Berryman v Solicitor-General [2008] 2 NZLR 772 (HC) at [2].

110 In the matter of an inquest into the death of Halatau Kianamanu Naitoko NZCorC Auckland CSU-2009AUK-000144, 23 August 2011 at [4]. 
marginalising its community importance and effectiveness". ${ }^{111}$ Moreover, fairness to participants is ensured in a variety of ways.

First, if the coroner proposes to make an adverse comment about a party, reasonable steps must be taken to notify the affected party and provide them with an opportunity to be heard. ${ }^{112}$ Secondly, coroners usually exclude evidence in practice if its probative value is outweighed by its prejudicial effect, or if it is irrelevant. ${ }^{113}$ Thirdly, coroners appear to be highly aware of the possibility that their comments and recommendations may imply blame, and routinely reiterate in their findings that the purpose of inquiries is not to apportion liability. ${ }^{114}$ Lastly, most recommendations aim to remedy systemic problems, even where individual errors and oversights have been established on the evidence. One example of this is the Ashton case, discussed in Part IV.A.1, where it was found that: 115

... there were a series of mistakes made by individuals and that, more significantly, the systems, policies and practices of the Department of Corrections and Police at the material time were inadequate and contributed to the events which culminated in Ms Ashton's death.

Coroner Evans concluded that human error (despite being an "inevitable" occurrence) was something that could have been detected through "more effective supervision and processes designed to minimise the risk". ${ }^{116}$ The systemic focus adopted by coroners can thus afford significant protection to individuals by minimising opportunities for the implicit allocation of blame.

\section{Lack of Expertise}

One of the main criticisms of coroners' recommendations is that it is inappropriate for judicial officers with predominately fact-finding responsibilities to make far-reaching proposals for

111 Graeme Johnstone "An Avenue for Death and Injury Prevention" in Hugh Selby (ed) The Aftermath of Death (Federation Press, Sydney, 1992) 140 at 145.

112 Coroners Act 2006, s 58(3).

113 Johnstone, above n 111, at 144; Coroners Act 2006, s 79(2). This approach aligns with the key principles in ss 7 and 8 of the Evidence Act 2006, which relate to the general admissibility and exclusion of evidence.

114 For instance, in an inquest into the deaths of the Kahui twins, Coroner Evans stressed several times throughout the finding that the Court was only concerned with findings of fact, as the twins' father, Chris Kahui, had already been tried and found not guilty of their murder. See In the matter of an inquest into the death of Cru Omeka Kahui, Infant NZCorC Auckland COR12/0020, 2 July 2012; In the matter of an inquest into the death of Christopher Arepa Kahui, Infant NZCorC Auckland COR12/0019, 2 July 2012 at [17], [18] and [184].

115 In the matter of an inquest into the death of Debbie Marie Ashton, above n 67, at [25] (emphasis added).

116 At [26]. 
reform. ${ }^{117}$ Nowadays, coroners are expected to undertake an increasingly multi-faceted administrative role in managing the death investigation process, which is "above a skill level generally found among judicial officers". ${ }^{118}$ Coroners must also be capable of evaluating complex medical, technical and scientific evidence, so as to amalgamate divergent non-legal perspectives into sensible recommendations capable of practical implementation. ${ }^{119}$ As has been observed by Ian Freckelton, "such a skill set is not easily found, let alone in one individual". ${ }^{120}$

The perceived inability of coroners to cope with specialist evidence has been dealt in the United States and Canada by replacing the coronial system with medical examiner systems, led by medical practitioners. ${ }^{121}$ Regardless of whether investigations are led by medical or legal professionals, effective coordination between the "medical" and "circumstantial" investigations of deaths is more likely to be accomplished if one official has oversight over the entire process. ${ }^{122}$ It is unnecessary for one official to be actively involved in the details of both kinds of investigation, but one official should be responsible for both and viewed as impartial by the public. ${ }^{123}$

It is suggested that legal professionals are more suited for this role. Coroners must exercise many judicial functions and preside over inquiries involving cross-examination and submissions from legal counsel. ${ }^{124}$ Knowledge of legal principles is crucial in conducting inquiries, ${ }^{125}$ particularly where cases require analysis of the relevant legislative or regulatory framework. ${ }^{126}$ For example, the inquest into the sinking of the $O$ Yang 70 involved issues of maritime law, including New Zealand's regulatory role as coastal state with the right to control fishing activity in the Exclusive Economic Zone. ${ }^{127}$

117 Ian Freckelton "Death investigation, the coroner and therapeutic jurisprudence" (2007) 15 JLM 1 at 4.

118 Freckelton and Ranson, above n 6, at 718.

119 Freckelton, above n 117 , at 8 .

120 At 8 .

121 Michael King and others Non-Adversarial Justice (The Federation Press, Sydney, 2009) at 202. However, practices vary according to jurisdiction, and some American states and Canadian provinces still have coroners.

122 Brodrick Committee Report of the Committee on Death Certification and Coroners (HMSO, Cmnd 4810, 1971) at [9.54].

123 At [9.55].

124 Law Commission, above n 13, at [35].

125 At [36].

126 Luce Committee, above n 8, at 78.

127 In the matter of an inquiry into the death of Yuniarto Heru, Samsuri, Taefur NZCorC Wellington CSU2010-CCH-000579, 6 March 2013 at [11]. 
An understanding of evidential rules is also vital, for instance where there are witness credibility issues or contradictory evidence. ${ }^{128}$ As discussed, although coroners may admit any evidence for the purposes of the inquiry, ${ }^{129}$ "many of the common sense rules of evidence must be applied if the fact-finding process is to assume any integrity". ${ }^{130}$ A higher proportion of time is expended upon evaluating expert evidence in the coroner's jurisdiction than in probably any other judicial context. ${ }^{131}$ This, along with the increasingly legalistic nature of inquests due to counsel representing parties more frequently at inquests, arguably warrants the appointment of legal rather than medical professionals to supervise the coronial process. ${ }^{132}$

\section{Lack of Consistency}

One issue inherent in formulating recommendations from findings is that recommendations arise on a case-by-case basis and are inevitably influenced by problems raised by individual cases. ${ }^{133} \mathrm{~A}$ key challenge that coroners face is to refrain from making far-reaching recommendations where there is insufficient evidence to support their proposals, whilst still offering solutions with some broader social benefit. ${ }^{134}$

This task is made more difficult by the lack of an official reporting system for coronial decisions. Coroners do already refer to previous coronial findings in identifying trends in dangerous practices and formulating recommendations. ${ }^{135}$ For instance, in a number of cases involving SUDI or SIDS, coroners have essentially reiterated recommendations from previous cases ${ }^{136}$ (albeit

128 This was an issue in the Natasha Harris case, where Coroner Crerar had to assess a number of conflicting expert accounts in determining whether excessive Coca Cola consumption contributed to the deceased's fatal arrhythmia. See An inquiry into the death of Natasha Marie Harris, above n 49, at [28].

129 Coroners Act 2006, s 79(1).

130 Ian Freckelton "Expert Proof in the Coroner's Jurisdiction" in Hugh Selby (ed) The Aftermath of Death (Federation Press, Sydney, 1992) 37 at 45. For instance, in the Barlow inquest, above n 101, the deceased's parents applied to exclude expert evidence on the basis that the expert in question "lacked independence". Coroner Matenga was subsequently required to consider principles underlying the admissibility of expert opinion evidence in deciding whether to allow the application.

131 Freckelton, above n 130, at 37

132 Law Commission, above n 13, at [35]. See also Appendix One, Table 4.

133 Freckelton and Ranson, above n 6, at 738.

134 At 738 .

135 Coroners referred to previous coronial decisions in 11 per cent of the cases examined. See Appendix One, Table 2 .

136 See for instance In the matter of an inquest into the death of Alexis Green, an infant, above $\mathrm{n} 46$; In the matter of an inquest into the death of Rakaua Rawhira Rongen NZCorC Invercargill CSU-2011-DUN000435, 7 August 2012; In the matter of an inquest into the death of Baby J NZCorC Rotorua CSU-2010ROT-000045, 13 June 2012; In the matter of an inquest into the death of Tahi Elvis Edwards NZCorC 
sometimes adapting their recommendations to the individual circumstances of the case before them) ${ }^{137}$ However, the absence of an official reporting system impedes the ability, not only of coroners, but also of lawyers and researchers to identify common themes between cases, thus making the task of prevention more difficult and time-consuming than it needs to be. ${ }^{138}$

\section{E Overlap with Other Investigating Authorities}

The coroner's role in death prevention has become a prominent characteristic in the evolution of the coronial process, ${ }^{139}$ but other agencies with recommendatory functions are also equipped to undertake such a role. ${ }^{140}$ Various authorities have statutory responsibilities to enquire into the causes and circumstances of deaths, including the Independent Police Conduct Authority, ${ }^{141}$ the Civil Aviation Authority, ${ }^{142}$ and mortality review committees. ${ }^{143}$ The Act refers to 13 such authorities, as well as Royal Commissions and Commissions of Inquiry. ${ }^{144}$ Because of the similarities between the powers and functions of coroners and other investigating authorities, sometimes there can be confusion as to which authority should accept jurisdiction. The boundaries of the coroner's jurisdiction are also not explicitly defined in the Act, which can result in pointless investigations being conducted.

Rotorua CSU-2011-ROT-000008, 30 August 2012; In the matter of an inquiry into the death of Mason William Roy Fraser NZCorC Dunedin CSU-2011-DUN-000314, 10 December 2012; In the matter of an inquest into the death of Chesara Anna-Rose McMurdo NZCorC Invercargill CSU-2010-DUN-000348, 25 May 2012.

137 See In the matter of an inquest into the death of Alexis Green, an infant, above n 46, at [106]. The Coroner endorsed statements made by other coroners relating to safe sleeping education for babies, but tailored her recommendations "specifically in relation to the older baby". See also Office of the Chief Coroner of New Zealand Recommendations Recap - Issue 1 (Ministry of Justice, July 2012), which contains a specific study of this line of cases.

138 University of Otago "Otago law researchers suggest changes to improve Coroners' recommendations" (press release, 5 August 2013).

139 Freckelton and Ranson, above n 6, at 720.

140 At 756.

141 Independent Police Conduct Authority Act 1988, s 4.

142 Civil Aviation Act 1990, s 72A.

143 There are currently four mortality review committees in New Zealand: the Child and Youth Mortality Review Committee, the Perinatal and Maternal Mortality Review Committee, the Family Violence Death Review Committee and the Perioperative Mortality Review Committee. All of the Committees were established under ss 11 and 18 of the New Zealand Public Health and Disability Act 2000.

144 Section 9, definition of "other investigating authority". 
The proliferation of specialist authorities, and the consequent erosion of the coroner's role and responsibilities, ${ }^{145}$ begs the question whether coroners are the best placed to be making recommendations or whether they are simply creating unnecessary bureaucracy. ${ }^{146}$ Nonetheless, it is important to remember that coroners' constitutional status is fundamentally different to that of administrative or government agencies. ${ }^{147}$ Coroners are independent judicial officers, so their jurisdiction is "judicial and wholly untrammelled", unlike other agencies whose investigations are more restricted in function and scope. ${ }^{148}$ As such, the investigating coroner, involved in all aspects of the case, is able to take into account the bigger picture and is well placed to evaluate future risks. ${ }^{149}$ Further, inquiries into sudden deaths or deaths in custody are arguably best conducted "under the auspices of someone who is independent of the medical profession, of the police and of 'government' in its widest sense". ${ }^{150}$ This ensures public confidence in the findings of the inquiry, as internal investigations may not be seen as entirely detached from the circumstances of the death.

\section{F "Stale" Recommendations}

Cases involving an inquest or a hearing on the papers generally take over 400 days to complete, ${ }^{151}$ and over 700 days if the inquiry is adjourned while another investigation is being undertaken. ${ }^{152}$ The length of time taken to complete coronial cases is influenced by a multitude of factors. Information must be collected from numerous sources and by different officials, depending on the circumstances of the case. ${ }^{153}$ If a person is charged with a criminal offence in relation to the death, and the coroner considers that an inquiry might prejudice that person, the coroner will typically adjourn the inquiry until criminal proceedings have concluded. ${ }^{154}$ The mandatory

145 Law Commission, above n 13, at [95].

146 Freckelton and Ranson, above n 6, at 738.

147 Law Commission, above n 13, at [97].

148 At [100]-[101].

149 Graeme Johnstone "Coroner's inquiries and recommendations" in Hugh Selby (ed) The Inquest Handbook (Federation Press, New South Wales, 1998) 38 at 42.

150 Brodrick Committee, above n 122, at [9.56].

151 Hearings on the papers may be conducted under s 77 of the Coroners Act if the coroner is satisfied that no person wishes to give evidence in person for the purposes of the inquiry.

152 Cabinet Paper, above n 4, at [28]. Section 69 of the Coroners Act sets out the relevant procedure to be completed if another investigation is being or is likely to be conducted. See also Appendix One, Table 1. Even if no inquiry is necessary, cases take approximately 133 days to be closed. No inquiry is necessary in around 55 per cent of cases, typically where death is found to be from natural causes.

153 Cabinet Paper, above n 4, at [29].

154 Section 68(6) provides that criminal proceedings are only finally concluded if no appeal or further appeal can be made in the course of the proceedings. See for example In the matter of an inquest into the death of Debbie Marie Ashton, above n 67. Criminal proceedings were brought against the other driver for 
requirement to hold an inquest where there has been a death in custody or care ${ }^{155}$ has also resulted in unnecessary inquests where death has been due to natural causes. ${ }^{156}$

Delays in the completion of cases can prolong grief for families and postpones the benefits society derives from recommendations designed to improve public safety. ${ }^{157}$ This diminishes the relevance of some recommendations, causing them to become "stale". For instance, in the Glenn Mills inquiry, Coroner Greig noted that it was unnecessary to make recommendations to prevent further self-inflicted deaths at Mount Eden Men's Prison because the prison had closed prior to the inquest. ${ }^{158}$ Similarly, Coroner Shortland declined to make any recommendations following an inquiry into the death of Jacquelin Pukeroa, as St John Ambulance had already introduced new protocols to address systemic errors that had contributed to the death, following an internal review. ${ }^{159}$

Ensuring coronial processes are efficient is not straightforward given delays can occur at different stages and for diverse reasons. Coroners already have the ability to postpone or adjourn an inquiry if another investigating authority is conducting an investigation into the death which is likely to establish the deceased's identity and the cause and circumstances of death. ${ }^{160}$ Further, coroners are obliged to perform their duties without delay "so far as is consistent with justice and practicable". ${ }^{161}$ However, as is addressed in Part V.E, the Act could be amended to clarify the circumstances in which coroners have jurisdiction to conduct investigations into certain deaths.

Overall, many of the criticisms levelled at recommendations are either overstated or could be addressed through reforms to the coronial system. The following Part proposes suggestions for how the recommendation-making process might be improved.

manslaughter and various other offences. The coronial case was not completed until six years after the accident.

155 Coroners Act 2006, s 80(a)

156 Cabinet Paper, above n 4, at [57]. Fifty-eight per cent of deaths in custody since July 2007 appear to have been from natural causes. See for instance In the matter of an inquest into the death of Michael Lyndsay Grant NZCorC Invercargill CSU-2011-DUN-000173, 23 April 2012.

157 Cabinet Paper, above $\mathrm{n}$ 4, at [28].

158 In the matter of an inquest into the death of Glenn Richard Albert Mills NZCorC Auckland CSU-2009AUK-001614, 17 July 2012 at [85].

159 In the matter of an inquiry into the death of Jacquelin Pukeroa NZCorC Whangarei CSU-2008-WHG000156, 10 February 2013 at [91].

160 Coroners Act 2006, s 69.

161 Coroners Act 2006, s 5. 


\section{SUGGESTIONS FOR REFORM}

\section{A Better Guidance for Formulating Recommendations}

Awareness of the fact that recommendations may result in backlash from the agencies and organisations to whom they are directed, as well as the public, has led coroners to adopt different approaches when formulating recommendations. ${ }^{162}$ While one response has been to refrain from making recommendations unless they directly relate to the circumstances and evidence before the coroner, ${ }^{163}$ another has been to make recommendations in general terms, merely encouraging agencies and organisations to give consideration to issues highlighted in the findings. ${ }^{164}$ Recommendations of this nature have "limited value", as: ${ }^{165}$

The need for such policy review, and awareness of that need, almost certainly exist within the agency involved, whether or not the coroner makes such a general recommendation - thus, when the finding is delivered, its impact is very restricted.

However, the most inadvisable approach is the formulation of impractical, broad-based recommendations that are not justified on the evidence, as this serves only to undermine public confidence in the coronial system and detract from the force of more sensible proposals. Coroners should exercise caution when proposing wide-ranging reviews or legal reforms based on limited evidence and without clearly articulating in their findings how such measures would have prevented the relevant death. ${ }^{166}$ Particular care should be taken if the proposed changes could cause harm or are costly or intrusive. ${ }^{167}$ That said, some pragmatism is required: coroners should seek to obtain "sufficient information of sufficient quality to make the decision without being paralysed by a quest for perfection". 168

162 Freckelton and Ranson, above n 6, at 738.

163 See for instance In the matter of an inquest into the death of Jason Clint Martin Palmer, above $\mathrm{n} 92 ;$ In the matter of an inquiry into the death of Elizabeth Jill Gilbertson, above n 94.

164 See for instance In the matter of an inquiry into the death of Janet Dulcie Honey NZCorC Rotorua CSU2010-ROT-000081, 19 June 2012; In the matter of an inquiry into the death of Natalia Joy Hume NZCorC Christchurch CSU-2011-CCH-000973, 3 July 2012; In the matter of an inquiry into the death of Gwenyth Elaine Kingsbury NZCorC Wellington CSU-2010-WGN-000399, 29 January 2013; In the matter of an inquiry into the death of Justin James Newton NZCorC Christchurch CSU-2010-CCH-000515, 4 January 2013.

165 Freckelton and Ranson, above n 6, at 738.

166 Cabinet Paper, above n 4, at [20.2].

167 Harrison and Moller, above n 21, at 222.

168 At 222 . 
The quality of recommendations could be improved by providing coroners with express guidance on how to draft and formulate recommendations. In England and Wales, the Ministry of Justice has issued a Guidance Note advising coroners on when to make recommendations and what information to include in reports to relevant parties. ${ }^{169}$ The Note includes example paragraphs and details the process coroners should undertake if agencies fail to respond. ${ }^{170}$ The Chief Coroner may already issue practice notes to help achieve consistency in coronial decision-making, though this ability is rarely used. ${ }^{171}$ Alternatively, coroners could be required to participate in a specialised training programme as part of their ongoing education. ${ }^{172}$

The MOJ has proposed that the Act should be amended to ensure recommendations are specific to the case and evidence before the coroner. ${ }^{173}$ Such an approach would be inconsistent with the approach taken in overseas jurisdictions. Coroners in England and Wales have a wide remit to make recommendations to prevent any other deaths based on the evidence heard at inquest, not just where a similar death is likely to occur in the future. ${ }^{174}$ In Australian states such as Queensland and Victoria, coroners may make recommendations on any matter connected with the death, including recommendations relating to public health and safety or the administration of justice. ${ }^{175}$ Nevertheless, clarifying that coroners' recommendation-making powers are confined to the facts at issue would possibly help ensure that recommendations are being formulated in a well-reasoned, consistent manner. Broader issues which arise on the evidence but fall outside the scope of the inquiry could still be highlighted in coroners' findings and thus brought to key parties' attention without making a formal recommendation under s 57(3).

\section{B Increased Collaboration with Key Parties}

Increasing opportunities for collaboration between parties affected by coroners' recommendations prior to the release of findings would enable parties to "engage in cooperative, non-adversarial dialogue", which would "reduce the likelihood of defensive behaviour" and increase the chances of recommendations being implemented. ${ }^{176}$ Studies of reactions to legal processes have

169 Ministry of Justice (UK) Guidance for coroners on changes to Rule 43: Coroner reports to prevent future deaths (14 July 2008).

170 At [2.6]-[2.9] and [4.8].

171 Coroners Act 2006, s 132(1). Only one practice note has been issued thus far. See Neil Maclean (Chief Coroner) The Role of the National Duty Coroner (10 June 2013, Practice Note 2013/1).

172 Coroners Act 2006, s 7(b).

173 Cabinet Paper, above n 4, at [27.1] and [27.2]. See Coroners Amendment Bill 2014 (239-1), cl 30.

174 Coroners Rules 1984 (UK), r 43.

175 Coroners Act 2008 (Vic), s 72(2); Coroners Act 2003 (Qld), s 3(d).

176 Michael King "Non-adversarial justice and the coroner's court: A proposed therapeutic, restorative, problem-solving model" (2008) 16 JLM 442 at 461. 
consistently found that the more people participate "the fairer they view the process and the more they are able to accept what may be a disappointing outcome". ${ }^{177}$ Processes that enable anger and grief to be reframed into potentially constructive outcomes are also more likely to minimise the "deleterious effects of exclusion and alienation". ${ }^{178}$ For families especially, promoting higher levels of participation in the formulation of recommendations would help some to "make meaning" of the event by focusing on how the death might be used as a means of preventing other needless fatalities. ${ }^{179}$ A more inclusive process could be achieved in several ways.

\section{Provisional release of findings}

Where a coroner proposes to make an adverse comment, the coroner will usually release a copy of provisional findings to the affected party for comment prior to the inquiry's completion. Provisional findings could similarly be released to agencies and organisations affected by proposed recommendations before the inquiry's completion. Although some coroners already include parties in the formulation of recommendations, this practice varies across different regions. ${ }^{180}$ Consistency could be achieved by amending the Act to expressly permit coroners to release provisional findings in appropriate cases.

This would have numerous advantages, especially for government agencies. ${ }^{181}$ Parties would be able to consider the impact of the recommendations and take appropriate steps, including briefing relevant staff and managing any publicity invariably following the release of the coroner's findings. ${ }^{182}$ Submissions could be prepared detailing objections to the recommendations or

177 Freckelton, above n 117, at 6.

178 Thomas J Scheff "Community Conferences: Shame and Anger in Therapeutic Jurisprudence" (1998) 67 Rev Jur UPR 96 at 110-111; Freckelton, above n 117, at 8.

179 Geoffrey Glassock "Coping with Grief" in Hugh Selby (ed) The Aftermath of Death (Federation Press, Sydney, 1992) 186 at 196. Of course, family members should have the right to determine their level of participation in coronial processes, if any, depending on whether or not they are summoned by the coroner as witnesses in the inquiry.

180 Cabinet Paper, above n 4, at [26]. Such an approach has been proposed in the new s 57B in cl 30 of the Coroners Amendment Bill 2014. See for instance In the matter of an inquest into the death of Troy Macfarlane Adamson NZCorC Gore CSU-2011-DUN-000072, 25 May 2012; In the matter of an inquest into the death of Adam Barlow, above $\mathrm{n} 101$; In the matter of an inquest into the death of Richard John Barriball NZCorC Balclutha CSU-2010-DUN-000364, 30 April 2012. See generally Appendix One, Table 2 .

181 There is also evidence of private companies adopting this approach. See for instance In the matter of an inquiry into the death of Geok Ling Phang NZCorC Wellington CSU-2009-WGN-000626, 19 March 2013; In the matter of an inquiry into the death of Rebecca Louise Stockwell NZCorC Hastings CSU-2008-CCH000165, 29 May 2012; In the matter of an inquiry into the death of Brendon Edward Walker NZCorC Christchurch CSU-2012-CCH-000077, 28 January 2013; In the matter of an inquiry into the death of William Stuart Dalzel McLay NZCorC Wellington CSU-2009-WGN-000189, 23 July 2012.

182 Law Commission, above n 13, at [187]-[190]. 
improvements that could be made, as well as any steps already undertaken to prevent similar deaths. While this process might add time and cost to some cases, agencies would be able to assess the proper level of involvement on a case-by-case basis. ${ }^{183}$

Giving organisations the opportunity to cultivate a positive public image also provides an incentive to act promptly following the death to identify and remedy hazards, even before the completion of the coronial inquiry. For instance, at the time of her death from SUDI, Baby Alexis was in the care of "Mrs A", a caregiver approved by Child, Youth and Family (CYF). ${ }^{184}$ Baby Alexis had been placed in Mrs A's care despite the fact that Mrs A was best suited to providing transitional care for seven to ten-year-old girls and had a low awareness of safe sleeping practices for infants. ${ }^{185}$ Two weeks after Baby Alexis's death, the Regional Director of the Southern Region of CYF took action and circulated information amongst site managers about the risks of SUDI, safe sleeping arrangements and necessary practice changes. ${ }^{186}$ Although Coroner Johnson noted that these measures were only the "first step" in preventing similar deaths, she commended the implementation of this local practice and, in particular, the speed with which it had been enforced. ${ }^{187}$

Allowing parties to comment in advance would also help ensure that recommendations are wellinformed and practical, which in turn would increase the possibility of implementation. Recommendations are more likely to be confined to the circumstances of the case where organisations and agencies offer input. This would reduce the number of recommendations proposing wide-ranging legal and policy reforms, which in turn would help prevent families and the public from forming unrealistic expectations as to what changes can be made to prevent future deaths.

Despite these advantages, care would need to be taken to consult all appropriate parties, as "the notion of private communication with only some of those represented at the hearing is incompatible with the exercise of judicial functions and the concepts of natural justice". ${ }^{188}$ Proper consultation

183 Cabinet Paper, above n 4, at [25].

184 In the matter of an inquest into the death of Alexis Green, an infant, above n 46, at [28].

185 At [81].

186 At [103].

187 At [104]. See also In the matter of an inquiry into the death of Antoine Roni Dixon NZCorC Wellington CSU-2009-AUK-000201, 17 April 2013 at [109], where the Coroner commended the Department of Corrections for the open-minded way in which it approached the giving of evidence and its review of the responsibilities it owed to the deceased.

188 Law Commission, above n 13, at [181] and [191]. This was the reason a similar proposal to implement a reporting regime with a right of reply to proposed recommendations was not accepted during the Law Commission's review of the coronial process in 2000. Similar concerns were raised in Matthews v Hunter, above n 103, where the plaintiff sought to quash the findings of a coroner who had engaged in private 
may be difficult to achieve before the inquiry's conclusion when all the evidence has not yet been heard, and also where recommendations are focused on ameliorating broader social and legal issues that affect multiple organisations. However, the holding of pre-inquest conferences and amending provisions in the Act relating to interested parties will help identify those who may wish to comment on recommendations.

\section{Better notification of interested parties}

Although coroners must give persons or organisations with an interest in the death notice of significant matters relating to the inquiry, ${ }^{189}$ interested parties are not always informed of inquiries that affect them or given the chance to assist in formulating recommendations. ${ }^{190}$ Usually the coroner is in the best position to ascertain who should be included in the inquiry. In high profile cases involving an inquest, the relevant agencies and organisations will generally be involved from the outset, so it is easy to ascertain their interest. ${ }^{191}$ However, in cases where there is limited government involvement, or where the inquiry proceeds by way of a chambers finding, it may be difficult to notify all appropriate parties prior to the inquiry's conclusion. ${ }^{192}$

The MOJ review has proposed strengthening s 23 of the Act to require the coroner to consider which individuals and organisations may have an interest in the death and should be notified of the inquiry so they can give evidence. ${ }^{193}$ The Coroners and Justice Act 2009 (UK) contains a definition of "interested person", which provides coroners with detailed instructions on who should be notified of the inquiry. ${ }^{194}$ Similarly, the Coroners Act 2003 (Qld) provides examples of parties who might have a sufficient interest, such as specialist advocacy groups with particular expertise on matters

consultation with two witnesses during an inquest. Although Heron $\mathbf{J}$ did not consider that the circumstances of the case gave "such an appearance of partiality as to justify the quashing of findings", he noted that conferring with the two witnesses in the absence of the other parties had been "unwise" and should not have occurred.

189 Coroners Act 2006, s 23. This provision also requires the coroner to notify immediate family or an elected family representative of significant matters.

190 Cabinet Paper, above n 4, at [20.3].

191 Johnstone, above n 111, at 159.

192 Inquiries may proceed by way of a chambers finding under s 77 of the Coroners Act 2006. Chambers findings are a fairly common occurrence. Between 2011 and 2012, 1,280 inquiries were opened, while 288 public inquests were held.

193 Cabinet Paper, above n 4, at [27.3].

194 Section 47. 
relevant to the inquiry. ${ }^{195}$ Inserting a similar definition of "interested party" into the Act would help coroners decide who should be notified of the inquiry. ${ }^{196}$

\section{Pre-inquest conferences}

Coroners regularly correspond with families prior to inquests to discuss procedures, but there is no statutory obligation to meet with parties pre-inquest. ${ }^{197}$ As with the provisional release of findings, practices are therefore inconsistent across different regions, resulting in uncertainty for agencies and organisations working in more than one place and making it difficult to prepare for inquests. 198

The practice of holding pre-inquest conferences should receive legislative recognition, so as to render it a formal element of the coronial process and to encourage consistency. Pre-inquest conferences have become a common feature in Queensland, where they have received statutory acknowledgement. ${ }^{199}$ They are essentially an administrative procedure akin to the case management regime in the civil context, ${ }^{200}$ designed to streamline the inquest. ${ }^{201}$ Although limited in scope, preinquest conferences can significantly reduce delays, particularly in complex inquiries. Further, holding conferences at such an early stage demonstrates to parties that their input in the process is valued, which promotes respect for coronial processes and sets a pattern for later consultation in respect to recommendations. ${ }^{202}$ The Queensland provision is an especially appealing model because it permits the publication of a notice at least 28 days in advance of the conference. ${ }^{203}$ This would be useful in alerting specialist organisations with an interest in the issues raised by the case (but not necessarily on the coroner's list of interested parties) of the intention to hold an inquest. These

195 Section 36.

196 Section 24 of the Act should also be amended to ensure that interested parties and family members automatically receive a copy of the coroner's findings and recommendations following the inquiry's completion. See Cabinet Paper, above n 4, at [27.9].

197 Fifteen of the cases examined as part of this paper indicated that the coroner had corresponded with family prior to the coroner's inquiry. See Appendix One, Table 2.

198 Cabinet Paper, above n 4, at [30].

199 Coroners Act 2003 (Qld), s 34. The coroner may hold a pre-inquest conference to determine the scope of the inquest, which witnesses and evidence will be required, and any other matters necessary to ensuring the orderly conduct of the inquest.

200 See generally High Court Rules, pt 7, subpt 1.

201 Freckelton and Ranson, above n 6, at 550.

202 King, above n 176, at 449.

203 Section 34(2). 
groups would then be sufficiently prepared to assist the coroner in formulating recommendations at the inquest. ${ }^{204}$

\section{Mandatory Response Provisions}

One way to ensure recommendations are not lost or ignored would be to make it mandatory for agencies and organisations to whom recommendations are directed to respond within a specified time. ${ }^{205}$ Various jurisdictions have already introduced mandatory response provisions and the Chief Coroner has endorsed such an approach. ${ }^{206}$ In Victoria, a response must be sent within three months specifying a statement of action (if any) that has, is or will be taken in relation to the recommendations. ${ }^{207}$ The coroner must subsequently publish the response online. ${ }^{208}$ Similarly, in England and Wales, agencies must respond by providing details of any action that has or will be taken, or an explanation as to why no action is proposed, within 56 days. ${ }^{209}$

Failure to provide a response is not an offence in either jurisdiction, though a "name and shame" approach is employed to encourage timely replies. ${ }^{210}$ This approach has been highly effective, and many responses are provided hastily following publication of a failure to respond. ${ }^{211}$ It is suggested that criticism through the media is the most appropriate sanction in this context. ${ }^{212}$ The media are less likely to put pressure on agencies to consider recommendations where they are under no obligation to consider recommendations in the first place, as is presently the case. Yet it is highly improbable that the media would let agencies off lightly after failing to comply with a legal duty to respond, especially government agencies. This process would be strengthened if coroners were willing to cultivate closer ties with the media, as there is "considerable scope for creative utilisation

204 Law Reform Commission of Western Australia, above n 38, at 145.

205 At the very least, agencies and organisations should be required to acknowledge receipt of the coroner's recommendations. If no acknowledgement is received, then either Coronial Services or the coroner should be responsible for resending the recommendations and confirming that they have been received.

206 Mike Watson "Plea not to let coroners' rulings wither" (22 March 2013) Stuff.co.nz <www.stuff.co.nz>; Shane Cowlishaw "Coroners' powers may be boosted" (1 August 2012) Stuff.co.nz <www.stuff.co.nz>. The University of Otago study has also found that every coroner, and all but two of the 79 organisations interviewed, supported mandatory response provisions. See University of Otago "Otago law researchers suggest changes to improve Coroners' recommendations" (press release, 5 August 2013).

207 Coroners Act (Qld), s 72(3).

208 Section 72(5).

209 Coroners (Amendment) Rules 2008 (UK), r 43A.

210 Law Reform Commission of Western Australia, above n 38, at 173-174; Alan Fletcher "Coroners' Rule 43 reports" (2011) 17(6) Clinical Risk 217 at 218.

211 Law Reform Commission of Western Australia, above n 38, at 174.

212 MacLeod, above n 34, at 94 
of publicity". ${ }^{213}$ The Health and Disability Commissioner (HDC), an independent ombudsman with recommendation-making powers within the public health system, ${ }^{214}$ regularly draws attention to matters of public concern by issuing media statements. ${ }^{215}$

One issue is whether it would be appropriate to subject private entities, such as private hospitals and companies, to such a regime. As the potential risk to the community is the same, it would make sense for mandatory response provisions to bind private bodies exercising public functions. ${ }^{216}$ Here, it is important to remember that compelling organisations to respond to recommendations "does not compel compliance with recommendations but does mandate responsiveness in the public interest and on the public record". 217

Mandatory response provisions would be a "powerful safeguard against apathy" and would have numerous collateral benefits. ${ }^{218}$ Public feedback on the practicality of recommendations would act as a quality control mechanism by encouraging coroners to formulate workable proposals and to seek specialist advice in appropriate cases. ${ }^{219}$ Agencies regularly involved in coroners' inquiries would be more likely to establish standard procedures for receiving and responding to recommendations, which would help prevent recommendations from being lost in the bureaucratic process. The extent to which recommendations are implemented could be more easily monitored, which would further consolidate the role of coroners in death prevention. ${ }^{220}$ Finally, the knowledge that recommendations have received proper consideration from the relevant agency or organisation may help families to draw some comfort from the fact that their loved one's death led to change beneficial to the community. ${ }^{221}$

\section{Restorative Justice Conferences}

Restorative justice conferences (RJCs) do not presently form part of the coronial process. ${ }^{222}$ Michael King has contended that restorative justice processes are particularly applicable to coronial

213 Freckelton and Ranson, above n 6, at 743.

214 Health and Disability Commissioner Act 1994, ss 45(2)(a) and (b).

215 Ron Paterson "The Patients' Complaints System in New Zealand" (2002) 21(3) Health Affairs 70 at 75.

216 Law Reform Commission of Western Australia, above n 38, at 173.

217 Freckelton, above n 28, at 583.

218 Fletcher, above n 210, at 217

219 Law Reform Commission of Western Australia, above n 38, at 171.

220 Freckelton, above n 28, at 583.

221 Freckelton, above n 28, at 583; King, above n 176, at 462.

222 Restorative justice has traditionally focused on the restoration of victims, offenders and communities within the criminal justice system. Informal meetings do occasionally occur between parties following the release of the coroner's findings. See for instance In the matter of an inquiry into the death of Gwenyth Elaine 
cases, in that they may fulfil the need of some families to confront the individual, agency or organisation directly or indirectly responsible for their loved one's death, to obtain an explanation of their conduct and to gain an apology. ${ }^{223}$ RJCs could act as an effective accountability mechanism by allowing families to follow up on whether the coroner's recommendations have been implemented after the inquiry. For this process to be effective, cases should be properly screened for suitability. ${ }^{224}$ It may, for instance, be inappropriate for a conference to be held where the coroner's recommendations are adamantly opposed. ${ }^{225}$ Families may be left frustrated and disillusioned with the coronial process where recommendations have simply been ignored.

Alternatively, separate RJCs could be conducted - one to address the matters specific to the deceased and their family, and another to focus on any recommendations relating to public health or safety. ${ }^{226}$ At the latter type of conference, community organisations and representatives with a legitimate interest in the case could be invited to discuss the coroner's findings and decide how best to implement any recommendations, alongside any family members who wished to attend. ${ }^{227}$ This approach would enable the coronial process to be more responsive to issues affecting specific communities. For instance, following the death of a seven-day-old baby in Martinborough from SUDI, it was reported that SUDI disproportionately affects Māori families in the Wairarapa. ${ }^{228}$ After the coroner's inquiry, a RJC could have been held so that kaumātua (Māori elders) and specialist organisations, such as Plunket, Tamariki Ora Well Child Service and Whakawhetu (a national kaupapa Māori organisation dedicated to the reduction of Māori SUDI deaths) could have collaborated and developed strategies to reduce SUDI deaths amongst Māori families in the area.

Kingsbury, above n 164, where meetings were scheduled between the deceased's family and the local DHB to discuss concerns over the deceased's care.

223 King, above n 176, at 454-455.

224 At 455. Care must also be taken to ensure that restorative processes are structured to minimise any power imbalances, particularly where all parties are not legally represented. See John Braithwaite "Restorative Justice and Therapeutic Jurisprudence" (2002) 38(2) Crim LB 244 at 248.

225 King, above n 176, at 455 .

226 At 457.

227 Restorative processes have increasingly involved stakeholders apart from the victim and the offender, including the extended family of the victim and the offender, as well as representatives or affected members of the community. See Braithwaite, above n 224, at 246.

228 Vomie Springford "Baby's death prompts coroner warning" Wairarapa Times-Age (online ed, Wairarapa, 23 May 2013). Concerns about Māori mortality rates have also been raised in the context of butane-related deaths and youth suicide. See generally Kurt Bayer "Govt needs to move on butane abuse - coroner" The New Zealand Herald (online ed, New Zealand, 25 July 2013); "Iwi seek to save future leaders from suicide" (28 August 2013) Radio New Zealand <www.radionz.co.nz>. 


\section{E Refining the Coroner's Investigative Function}

As discussed in Part IV, the fact that coroners' inquiries often occur months or years after the death: ${ }^{229}$

... reduces the immediacy of the coronial response, allows distress and anger to fester on the part of family and community members, and takes the sting out of recommendations by coroners for change...

Delays could be reduced by not only refining the coroner's statutory role in relation to certain kinds of deaths, but also by clarifying the coroner's relationship with other investigative authorities. Although a full discussion of such measures is beyond the scope of this article, a brief summary of possible reforms is called for.

First, delays in investigations of medical-related deaths could be addressed by amending the legislative definition of "medical-related deaths" in the Act. ${ }^{230}$ The current definition encompasses almost every medical-related death ${ }^{231}$ and does not reflect cases where death is highly likely due to terminal illness, multiple chronic conditions or incidents involving emergency surgery. ${ }^{232}$ As a result, medical practitioners often need to contact the coroner to discuss whether the death should be reported and the coroner should take jurisdiction. ${ }^{233}$ In Australian jurisdictions such as Victoria and Queensland, coroners only have jurisdiction to investigate medical-related deaths where a medical practitioner would not have expected the relevant health care to contribute to the death or for the death to occur at that time. ${ }^{234}$ All circumstances relating to the death, such as whether the deceased suffered from an underlying condition or injury, may be examined. ${ }^{235}$ Refining the definition of "medical-related deaths" in the Act in a similar fashion would ensure the coronial process is focused on cases that warrant investigation by a judicial officer. ${ }^{236}$

Secondly, the MOJ review has proposed removing the mandatory requirement to hold an inquest where there has been a death in official custody or care. ${ }^{237}$ Requiring an inquest in these cases is

229 Freckelton and Ranson, above n 6, at 749.

230 Sections 13(1)(c) and 13(1)(d).

231 Cabinet Paper, above n 4, at [50].

232 At [50].

233 At [50].

234 Coroners Act 2008 (Vic), s 4(2)(b); Coroners Act 2003 (Qld), s 10AA(2)(b).

235 Section 10AA(4).

236 The MOJ has recommended that the definition of medical-related deaths should also be formulated in consultation with relevant health sector officials. See Cabinet Paper, above n 4, at [83].

237 At [57]. 
unnecessarily time-consuming where deaths appear to be from natural causes. ${ }^{238}$ A potential danger of removing this requirement is that community concerns over deaths in state care may not be resolved where it is felt that cases have received less scrutiny from an independent body. ${ }^{239}$ However, multiple other safeguards exist which would ensure these deaths still received proper examination. For instance, it is standard practice for an inspector of corrections to investigate all deaths in custody irrespective of cause. ${ }^{240}$ The Chief Ombudsman subsequently reviews the investigator's report to verify that the investigation was properly conducted. ${ }^{241}$ In any case, coroners will still be required to open an inquiry into all deaths in custody and care, ${ }^{242}$ and retain the discretion to hold an inquest where this is considered necessary. ${ }^{243}$

Finally, clarifying the circumstances where coroners should accept jurisdiction and where they should refer cases to other investigating authorities could reduce needless duplication between coroners and other authorities. ${ }^{244}$ For instance, the HDC signed a Memorandum of Understanding with the Office of the Chief Coroner in 2009, which has improved co-ordination in investigations of medical-related deaths. ${ }^{245}$ One of the Chief Coroner's main functions is to "help avoid unnecessary duplication and expedite investigation of deaths by liaison, and encouragement of coordination...with other investigating authorities". ${ }^{246}$ This provision could be strengthened by

238 At [57]-[58]. Fifty-eight per cent of the 78 deaths in custody since 2007 appear to have been from natural causes.

239 At [60].

240 Beverley Wakem and David McGee Ombudsman Act Investigation of the Department of Corrections in relation to the Provision, Access and Availability of Prisoner Health Services (2012) at 22. Inspectors are independent from prisons and report to the Assurance Board, but are still part of the Department of Corrections. See Review of Prisoner Complaints Processes (Ministry of Justice, April 2005) at [1.4] and [1.10]. Other independent authorities, such as the HDC and the Children's Commissioner, may also investigate deaths that occur in care or custody under s 40 of the Health and Disability Commissioner Act 1994 and ss 12(1)(a) and 13(1) of the Children's Commissioner Act 2003 respectively.

241 Wakem and McGee, above n 240, at 22. An Ombudsman can also choose to conduct his or her own independent investigation, though this has never been considered necessary.

242 Coroners Act 2006, s 60(1)(a)(ii).

243 Cabinet Paper, above n 4, at [60]. Pursuant to s 77(1) of the Act, coroners may only hold a hearing on the papers instead of an inquest where satisfied that no person from whom evidence is to be heard for the purposes of the inquiry wishes to give evidence in person.

244 Cabinet Paper, above n 4, at [40].

245 Office of the Health and Disability Commissioner Statement of Intent 2012/2015 (29 June 2012) at 16.

246 Coroners Act 2006, s 7(1). 
requiring the Chief Coroner to develop agreements with other investigating authorities for the purposes of clarifying their role in relation to coroners. ${ }^{247}$

\section{F Improving Transparency and Data Collection Processes}

\section{Official reporting system}

Establishing an official reporting system for coronial findings and recommendations would improve the consistency and transparency of coronial decision-making. The Chief Coroner currently maintains a public register containing summaries of recommendations through NZLII, a non-profit database, ${ }^{248}$ but it is acknowledged that the register is not particularly user-friendly. ${ }^{249}$ If accessibility were improved, it is likely that coronial findings and recommendations "will become subject to a level of scrutiny from which their anonymity and inaccessibility thus far have protected them", which in turn may result in decisions of a higher quality. ${ }^{250}$ Enhancing public access is also conducive to preventing similar deaths and would help alleviate community concerns about suspicious, sudden or unexpected deaths. That said, privacy considerations must be taken into account in determining the appropriate scope of publication, especially where families object to publication.

Even though findings and recommendations become part of the public record once the inquiry is concluded, determining whether to suppress evidence, or to allow the circumstances of self-inflicted deaths to be published, is also a recognised aspect of the coroner's role. ${ }^{251}$ Stringent restrictions exist preventing the publication of certain details of self-inflicted deaths without the coroner's permission, and coroners regularly suppress the names or identifying details of witnesses. ${ }^{252}$ Postmortem photographs are routinely subject to non-publication orders, ${ }^{253}$ and the availability of

247 Cabinet Paper, above n 4, at [42.1]. Compare for instance s 160 of the Corrections Act 2004, which explicitly requires the Chief Executive of Corrections to develop a protocol with the Chief Ombudsman about the assistance to be provided by the Chief Executive to the Ombudsman.

248 The Chief Coroner is obliged to maintain a public register of recommendations under s 7(i) of the Act.

249 Neil MacLean "Coronial reform and the role of the Chief Coroner" [2012] NZLJ 207 at 209.

250 Freckelton and Ranson, above n 6, at 736.

251 Coroners Act 2006, s 4(1)(e)(ii).

252 Coroners Act 2006, s 74. See Appendix One, Table 3. The High Court's decision in Gravatt v Auckland Coroner's Court [2013] NZHC 390, [2013] NZAR 345 may, however, decrease the number of nonpublication orders made in relation to the names of witnesses. In that case, the High Court held that suppression could not be approached in a "broad brush way" and that coroners needed to provide clear reasons for their decision on the basis of one of the grounds in s 74. Under this provision, a non-publication order may be made if this is in in the interests of justice, decency, public order, or personal privacy.

253 See Appendix One, Table 3. 
sensitive coronial documents, such as pathologist reports, is subject to both the Privacy Act 1993 and the Official Information Act 1982. ${ }^{254}$

Determining the proper scope of publication may be characterised as a competition between private and public interests, but it must be remembered that there is a strong public interest in protecting privacy. ${ }^{255}$ The unnecessary public disclosure of inquest details can result in reputational and employment consequences for those involved in the proceeding, as well as distress and humiliation. Unwarranted intrusions into privacy can interfere with the dignitary interests of the deceased $^{256}$ and exacerbate the trauma suffered by families. ${ }^{257}$ The weight attributable to privacy interests will ultimately depend on the facts of each individual case. In some cases, privacy interests will outweigh the public interest in the circumstances of the death. For instance, in the case of TC, Coroner na Nagara considered that prohibiting publication of the deceased's name, despite being an unusual step, was justified in order to protect the dignity of TC's memory and the privacy of his family and friends. ${ }^{258}$ The Coroner emphasised that the significance of the case lay, not in the identities of those involved, but in raising public awareness about suicide prevention. ${ }^{259}$ Nevertheless, sometimes the public interest in the circumstances of the death will outweigh privacy considerations. In the McGuinness inquest, the deceased's family members sought permanent suppression of the deceased's name. ${ }^{260}$ Although Coroner Smith "struggled" with the application, he

254 Coroners Act 2006, s 29(2). Under s 28 any person may access certificates of coroner's findings, even where the coroner has prohibited the publication of evidence given during the inquiry. However, although a copy of findings may be obtained, any restrictions imposed on publication under s 71 or s 74 still apply.

255 Stephen Penk "Thinking about Privacy" in Stephen Penk and Rosemary Tobin (eds) Privacy Law in New Zealand (Brookers Ltd, Wellington, 2010) 1 at 19.

256 At 4 . Note that Penk and Tobin raise the idea of privacy as an aspect of human dignity as only one possible conception of privacy.

257 For examples of studies that have examined the impact of coronial procedures and bereavement on families, see Lucy Biddle "Public hazards or private tragedies? An exploratory study of the effect of coroners' procedures on those bereaved by suicide" (2003) 56 Social Science \& Medicine 1003; Daniel Harwood and others "The grief experiences and needs of bereaved relatives and friends of older people dying through suicide: a descriptive and case-control study" (2002) 72 Journal of Affective Disorders 185; Victoria Law Reform Committee, above n 104, at 546.

258 In the matter of an inquiry into the death of TC NZCorC Palmerston North CSU-2009-PNO-000260, 23 July 2012, at [55].

259 At [51]-[52]. See also In the matter of an inquiry into the death of Baby L NZCorC Wellington CSU-2008WGN-000089, 25 July 2012. In that case, the family requested that Coroner Smith prohibit publication of the deceased's name due to the possible trauma the deceased's sibling might suffer from any such publicity. Although Coroner Smith noted that it was relatively rare for coroners to prohibit publication of the deceased's name, and that this power should only be exercised very sparingly, he concluded that a nonpublication order was appropriate in the circumstances.

260 In the matter of an inquest into the death of Leigh Galvin McGuinness NZCorC Wellington CSU-2008WGN-000754, 14 January 2013. 
emphasised that permanent prohibition should only be made in "very extraordinary circumstances", a threshold which had not been met on this occasion. ${ }^{261}$ In the end, it was crucial for the public to be warned about issues that had emerged at the inquest concerning the provision of deficient mental health care. ${ }^{262}$

Coroners could raise the subject of non-publication orders at pre-inquest conferences so that families are given an opportunity to air concerns at an early stage. Sensitive details that emerge during the inquiry, but are unrelated to the circumstances of the death, could simply be omitted from the coroner's formal findings. In the case of $\mathrm{Mr} \mathrm{M}$, the Coroner opted not to include the details of the deceased's suicide note in his findings, so as to avoid causing unnecessary distress to the deceased's family and friends. ${ }^{263}$

Although excluding irrelevant material from findings would be relatively straightforward, a more complex issue is whether the deceased should be identified in any official reports. The Family Court has posted anonymised decisions on its website since 2004 in an effort to increase public confidence in Family Court proceedings, ${ }^{264}$ while still preserving the "very necessary privacy" of families. ${ }^{265}$ In HDC reports, the names of almost every person and organisation involved in the inquiry are replaced with pseudonyms. ${ }^{266}$ However, wide-scale suppression is inconsistent with the "particular need" for openness in coronial inquiries. ${ }^{267}$ One could argue that the public interest is predominately served through recommendations aimed at safeguarding others in the community from similar deaths and that publishing the recommendations by themselves (as is currently done through NZLII) adequately fulfils this interest. Yet this overlooks the public interest in ascertaining the identity of the deceased, which forms part of the primary purpose of inquiries. ${ }^{268}$ It also removes recommendations from their factual context and thereby diminishes the transparency of coronial decision-making.

261 At [61].

262 At [59].

263 In the matter of an inquiry into the death of $M r M$ NZCorC Palmerston North CSU-2012-PNO-000310, 4 December 2012 at [3]-[4].

264 Pauline Tapp "Privacy Issues in the Family Court" in Stephen Penk and Rosemary Tobin (eds) Privacy Law in New Zealand (Brookers Ltd, Wellington, 2010) 277 at 279.

265 Peter Boshier, Principal Family Court Judge "New Pathways in the Family Court" (speech to Auckland District Law Society, Ellerslie Event Centre, Auckland, 22 September 2008).

266 Saul Holt and Ron Paterson "Medical-legal secrecy in New Zealand" (2008) 15 JLM 602 at 602.

267 Freckelton and Ranson, above n 6, at 605.

268 Coroners Act 2006, ss 4(2)(a) and 57(2). 
Another option would be to fully publish only a selection of significant findings. The selective reporting of important decisions involving matters of public interest is a common law reporting technique aimed at preventing an unlimited proliferation of decisions. ${ }^{269}$ However, the inherent public interest in the kinds of deaths reported to the coroner, such as deaths in custody or deaths without known cause, may warrant more extensive publication so as to properly allay public concern. ${ }^{270}$ Full findings could be released, but information subject to non-publication orders could be redacted. Although this may impede readability to some extent, it would strike an appropriate balance between the public interest in the circumstances of the death (including the deceased's identity) and any privacy interests the coroner has seen fit to protect.

\section{National coronial information system}

National information systems are immensely helpful to the coroner's role in death prevention. ${ }^{271}$ These databases allow coroners to quickly locate similar deaths and access details of investigations and findings, ${ }^{272}$ which assists in the identification of systemic or wide-ranging risk factors. ${ }^{273}$ The Case Management System (CMS), a national database for New Zealand coronial cases, was established in July 2007. ${ }^{274}$ New Zealand has also recently joined the National Coroners Information System (NCIS), a national database that records coronial information in Australia. ${ }^{275}$ Consequently, New Zealand cases will soon become available on the NCIS site - a promising step towards a "one stop shop" for Australasian coronial cases. ${ }^{276}$ Unlike CMS, NCIS stores the full text

269 JM Jacobstein "Some Reflections on the Control of the Publication of Appellate Court Opinions" (1975) 27 Stan L Rev 791 at 794. Supreme Court and Court of Appeal decisions of public interest are routinely published via the Courts of New Zealand website. See Courts of New Zealand "Judicial Decisions of Public Interest" <www.courtsofnz.govt.nz>. A handful of coronial findings deemed to be of "public interest" are in fact already available on the MOJ website, though this list has not been updated for some time. See Ministry of Justice "Coronial findings of public interest" <www.justice.govt.nz>. The most recent decision at the time of publication was dated 25 March 2013.

270 This was identified by the Brodrick Committee in 1971 as one of the public interests which should be fulfilled at inquest. See Brodrick Committee, above n 122, at [14.21]-[14.23].

271 Halstead, above n 20, at 206; Harrison and Moller, above n 21, at 67.

272 Harrison and Moller, above n 21, at 67.

273 Freckelton and Ranson, above n 6, at 829.

274 Ministry of Justice "Coronial data collection" <www.justice.govt.nz>. The CMS stores information on the person who died, how they died, and any contributing factors to their death. Summaries of police reports and the coroner's provisional and final findings also form part of the database, and data is drawn from pathologist reports, medical histories, witness statements and toxicology reports.

275 Smith Committee The Shipman Inquiry: Death Certification and the Investigation of Deaths by Coroners (HMSO, Cm 5854, July 2003) at [18.29].

276 MacLean, above n 249, at 209 
of police, pathologist and toxicology reports. ${ }^{277}$ This allows for more comprehensive statistical analysis, as un-coded text is often a "better way of conveying the subtleties and complexities of the events leading to injuries" and death than classified data. ${ }^{278}$ This is because text-searching techniques may reveal information not covered by standard classifications. ${ }^{279}$

Using databases such as NCIS on a routine basis would enable coroners to supplement records of New Zealand experience with international experience. ${ }^{280}$ Some coroners already refer to overseas research in their findings. During the Stephen Fitzgerald inquest, the Coroner took into account international research on cycling deaths when formulating recommendations. ${ }^{281}$ International access to national databases would also assist in the understanding of global, environmental, and community hazards, which could benefit various public health activities. ${ }^{282}$

There are, however, two main barriers to such a development. First, as with the publication of coroners' findings, privacy concerns must be taken into account in developing databases with broad access. ${ }^{283}$ NCIS data is available to coroners, government agencies and other organisations, but is not yet publicly available or even accessible to legal practitioners involved in the coronial process without the permission of the investigating coroner. ${ }^{284}$ Individuals and groups with a legitimate interest in public health may only gain access with ethics approval. ${ }^{285}$ However, the requirement for ethics approval may represent an appropriate balance between the public interest in transparency around coronial decision-making and privacy concerns about sensitive information in coronial documents, provided coroners' accountability could be ensured through other measures, such as an official reporting system. The second obstacle is that coroners' use of the NCIS thus far has been limited. ${ }^{286} \mathrm{~A}$ database search should be a standard part of the investigation, as this allows previously undetected patterns to be identified early on, thus providing information to shape the

277 National Coronial Information System "Data from coronial files" <www.ncis.org.au>.

278 James Harrison and Daniel Tyson "Preventing Injury" in Hugh Selby (ed) The Aftermath of Death (Federation Press, Sydney, 1992) 233 at 237.

279 At 237.

280 Johnstone, above n 149, at 49; Halstead, above n 20, at 206.

281 In the matter of an inquest into the death of Stephen Fitzgerald, above n 78, at [28].

282 Freckelton and Ranson, above n 6, at 106.

283 At 106.

284 National Coronial Information System "About NCIS" <www.ncis.org.au>; Freckelton and Ranson, above n 6 , at 734 .

285 National Coronial Information System "NCIS - Frequently Asked Questions" <www.ncis.org.au>. Subscription fees also apply.

286 Freckelton and Ranson, above n 6, at 734. 
"direction, scope and focus" of the subsequent inquiry. ${ }^{287}$ As coroners rarely have experience with statistics-based research techniques, unless specialists are employed fulltime by coroners' offices, "it seems unlikely that the available data sets will be mined in the way that their potential would allow". 288

A noteworthy initiative in the context of SUDI deaths was the development of a pilot programme between the $\mathrm{MOH}$ and Coronial Services in 2008. ${ }^{289}$ The programme established the role of SUDI Referral Advisors - health trained investigators who worked with coroners and other agencies to improve information collection for SUDI deaths and to provide ongoing support for families. ${ }^{290}$ Referral Advisors were also tasked with raising awareness of SUDI risk factors through training programmes. ${ }^{291}$ Developing similar initiatives in other types of cases would help ensure that crucial data is being collected to support preventive measures. Though such an initiative would depend on resourcing priorities, the cost is arguably justified given the potential of this data, if used properly, to help prevent future deaths.

\section{CONCLUSION}

The coroner's ability to make recommendations aimed at preventing needless fatalities within the community represents a "constructive and positive functioning of the law, moving outside the straightjacket of the adversary system". ${ }^{292}$ Recommendations carry particular therapeutic potential for families who have suffered a loss "otherwise hard to endure and for which the legal system may otherwise provide little in terms of solace" by redirecting families' focus towards constructive matters, specifically the avoidance of deaths in similar circumstances. ${ }^{293}$ Despite this, many recommendations are not implemented because they are perceived to be too costly, impractical and uninformed. The MOJ review's proposed legislative changes, which seek to focus recommendations on the case at hand, as well as increasing opportunities for collaboration and reducing delays, are a positive step forward and will help ensure coroners are making practical recommendations, soundly based in the evidence before them.

287 At 741 .

288 At 741 .

289 Child and Youth Mortality Review Committee Sixth Report on the Activities of the CYMRC: 1 January to 30 June 2011 (March 2012) at 13.

290 Barbara Wright "The Role of the SUDI Referral Advisor" Whakawhetu - National SUDI Prevention for Māori <www.whakawhetu.co.nz>.

291 Neil MacLean "Confessions of a Coroner" (speech to New Zealand Medical Association Practice Conference and Medical Exhibition, Rotorua, June 2013). Though feedback has been positive, the future of the programme is uncertain. See Child and Youth Mortality Review Committee, above n 289, at 13.

292 Freckelton, above n 117, at 4.

293 Freckelton and Ranson, above n 6, at 543. 
However, in many respects the proposed changes do not go far enough in maximising the coroner's preventive role. The quality of recommendations could also be effectively enhanced through extra-legislative measures, such as the development of an official reporting system and the increased use of databases. Further, the holding of RJCs would allow families to follow up on whether recommendations have been implemented, as well as allowing the coronial process to be more responsive to the needs of specific communities. Most significantly, the absence of any legal requirement to reply to coroners' suggestions continues to relieve those to whom recommendations are directed of the duty to be responsive. ${ }^{294}$ Where feasible recommendations are simply ignored, this is harmful to both the deceased's family and the wider community: families might be left disillusioned by the outcome of the process, while hazards revealed by the coroner's inquiry may result in needless fatalities within the community if left unremedied. Ultimately, greater transparency and accountability is needed for the potential of coroners' recommendations to be fully harnessed.

294 At 741. 


\section{APPENDIX ONE - TABLES AND CHARTS RELATING TO FINDINGS OF STUDY}

Table 1. Types of case by broad category

\begin{tabular}{|c|c|}
\hline Type of case & Number of cases \\
\hline $\begin{array}{l}\text { Transport-related } \\
\text { Alcohol or substance-related } \\
\text { Work-related }\end{array}$ & $\begin{array}{c}44 \\
(15) \\
(5)\end{array}$ \\
\hline $\begin{array}{l}\text { Self-inflicted } \\
\text { Mental health issues } \\
\text { Deaths in official custody }\end{array}$ & $\begin{array}{l}\mathbf{1 6} \\
(9) \\
(6)\end{array}$ \\
\hline $\begin{array}{l}\text { Water-related } \\
\qquad \begin{array}{l}\text { Drowning } \\
\text { Recreational/maritime accident } \\
\text { Alcohol-related }\end{array}\end{array}$ & $\begin{array}{c}15 \\
(4) \\
(10) \\
(1)\end{array}$ \\
\hline $\begin{array}{l}\text { SUDI/SIDS deaths } \\
\text { Deaths in official care }\end{array}$ & $\begin{array}{c}9 \\
(1)\end{array}$ \\
\hline Adverse reaction to medical/surgical treatment & 8 \\
\hline Labour or pregnancy-related & 2 \\
\hline Alcohol or substance-related & 4 \\
\hline Care facilities deaths & 2 \\
\hline $\begin{array}{l}\text { Natural causes } \\
\quad \text { Deaths in official custody }\end{array}$ & $\begin{array}{c}\mathbf{4} \\
(2)\end{array}$ \\
\hline $\begin{array}{l}\text { Alcohol-related } \\
\text { Recreational/leisure activities } \\
\text { Care facilities }\end{array}$ & $\begin{array}{l}\mathbf{8} \\
(2) \\
(4) \\
(1)\end{array}$ \\
\hline Homicide or interpersonal violence & 4 \\
\hline Work-related & 3 \\
\hline Accidental shootings & 2 \\
\hline Other & 3 \\
\hline Total & 124 \\
\hline
\end{tabular}


Table 2. General data relating to 124 cases

\begin{tabular}{|l|l|}
\hline $\begin{array}{l}\text { Inquests held } \\
\text { Joint inquests }\end{array}$ & $\begin{array}{l}\mathbf{5 5} \\
(3)\end{array}$ \\
\hline $\begin{array}{l}\text { Hearings on papers (chambers findings) } \\
\text { Joint hearings }\end{array}$ & $\mathbf{6 7}$ \\
\hline Average length of findings & 11 pages \\
\hline Average length between death and release of findings & 22 months \\
\hline Provisional findings released for adverse comment & 15 cases \\
\hline Reference to previous coronial cases in findings & $11 \%$ of cases \\
\hline Pre-inquest meeting conducted & $16.36 \%$ of inquests \\
\hline Pre-inquiry communications between coroner and deceased's family & $12.1 \%$ of cases \\
\hline Expression of condolences for family/friends of deceased in findings & $48.39 \%$ of cases \\
\hline
\end{tabular}

Table 3. Number of non-publication orders made by coroners

\begin{tabular}{|l|c|}
\hline Type of order & Number \\
\hline Prohibition in respect of evidence or witness details & 22 \\
\hline Prohibition of details relating to deceased (i.e. name, place of death) & 11 \\
\hline Prohibition on release of photos of deceased & 20 \\
\hline Reporting restrictions in self-inflicted cases (i.e. manner of death) & 12 \\
\hline Total & $\mathbf{6 5}$ \\
\hline
\end{tabular}


Table 4. Legal assistance provided in 124 cases*

$\begin{array}{ll}\text { Type of legal assistance } & \text { Percentage of cases }\end{array}$

Counsel for family

Counsel for public agency/local body (i.e. DHBs)

$13.71 \%$

Counsel for private organisation or company

$6.45 \%$

Counsel for individual (i.e. health practitioners)

$12.1 \%$

Counsel assisting the Court

$3.23 \%$

Table 5. Types of recommendations made in 124 cases

\begin{tabular}{lc}
\hline Type of recommendation made & Number of cases \\
\hline No formal recommendations & 45 \\
General warning to affected sections of the public & 28 \\
Formal recommendations & 79 \\
\hline
\end{tabular}

Table 6. Type of agencies, organisations and companies subject to recommendations

\begin{tabular}{|c|c|}
\hline Type of agency/organisation & Number of recommendations \\
\hline Government agencies & $\mathbf{8 0}$ \\
Ministry of Health & $(9)$ \\
Ministry of Social Development & $(15)$ \\
Ministry of Transport & $(10)$ \\
New Zealand Transport Agency & $(7)$ \\
Maritime New Zealand & $(9)$ \\
Ministry of Business, Innovation and & $(7)$ \\
Employment* & $(17)$ \\
Department of Corrections & $(1)$ \\
Department of Conservation & $(3)$ \\
Ministry of Housing & $(1)$ \\
Ministry of Consumer Affairs & $(1)$ \\
Ministry for Primary Industries & \\
\hline
\end{tabular}

* The accuracy of this information was dependent on the relevant parties being mentioned either in the findings themselves or in a list of attendees to the inquest.

** Formerly the Department of Labour. 


\begin{tabular}{|l|c|}
\hline Police and emergency services & 15 \\
\hline Care facilities & $\mathbf{7}$ \\
\hline Hospitals and DHBs & 19 \\
\hline Local authorities & $\mathbf{1 3}$ \\
\hline Private companies & $\mathbf{5}$ \\
\hline Other & 15 \\
\hline Total & $\mathbf{1 5 4}$ \\
\hline
\end{tabular}

Table 7. Extent of implementation of recommendations by agencies and organisations

\begin{tabular}{|l|c|}
\hline Extent of implementation & Percentage \\
\hline "Lost"/not referred to agency/organisation & $6.49 \%$ \\
\hline No response provided by agency/organisation & $7.79 \%$ \\
\hline Not implemented (i.e. impractical/too costly/unnecessary) & $30.19 \%$ \\
\hline Partial implementation/consultation ongoing & $16.88 \%$ \\
\hline Substantive implementation & $57.14 \%$ \\
\hline Changes made prior to coroner's inquiry & $2.6 \%$ \\
\hline
\end{tabular}

Table 8. Types of formal recommendations

\begin{tabular}{|c|c|}
\hline Type of recommendation & Number \\
\hline $\begin{array}{l}\text { Legal/regulatory changes } \\
\text { - Wide } \\
\text { - Narrow }\end{array}$ & $\mathbf{2 5}$ \\
$(21)$ \\
$(4)$ \\
\hline $\begin{array}{l}\text { Policy/protocol changes } \\
\text { - Wide }\end{array}$ & $\mathbf{4 1}$ \\
\hline
\end{tabular}




\begin{tabular}{|l|c|}
\hline - Narrow & $(19)$ \\
\hline $\begin{array}{l}\text { Educative } \\
\text { - Wide (i.e. public education campaigns) } \\
\text { - Narrow (i.e. specific training) }\end{array}$ & $\mathbf{4 0}$ \\
\hline $\begin{array}{l}\text { Practical changes } \\
\text { - Wide (i.e. product changes) } \\
\text { - Narrow (i.e. signage changes) }\end{array}$ & $\mathbf{3 1}$ \\
\hline $\begin{array}{l}\text { Investigation/review needed } \\
\text { - Wide }\end{array}$ & $(22)$ \\
- Narrow & $\mathbf{1 7}$ \\
\hline $\begin{array}{l}\text { Forwarding of findings to agencies for data collection } \\
\text { Total }\end{array}$ & $\mathbf{7})$ \\
\hline
\end{tabular}

Table 9. Use of external recommendations and suggestions by coroners in the formulation of recommendations

\begin{tabular}{|l|c|}
\hline Source of input & Number of cases \\
\hline Adoption of recommendations from prior investigation/review & 14 \\
\hline Informed by suggestions of counsel for family & 4 \\
\hline Informed by suggestions of counsel for other participants at inquest & 2 \\
\hline Endorsement of current practice by agency/organisation & 12 \\
\hline
\end{tabular}

Table 10. Other investigations, reviews and proceedings conducted prior to or concurrently with coronial inquiry***

\begin{tabular}{|l|c|}
\hline Type of review & Number of cases \\
\hline Police investigation & 17 \\
\hline
\end{tabular}

*** In some cases, several kinds of investigation were conducted prior to or concurrently with the coroner's inquiry. 


\begin{tabular}{|l|c|}
\hline Serious Crash Unit Investigation & 30 \\
\hline Criminal proceedings & 1 \\
\hline Disciplinary proceedings & 9 \\
\hline Health and Safety in Employment investigation & 3 \\
\hline Ministerial Inquiry & 4 \\
\hline Inspector of Corrections investigation & 1 \\
\hline Independent Police Conduct Authority investigation & 1 \\
\hline Ombudsman investigation & 21 \\
\hline Children's Commissioner investigation & 12 \\
\hline Internal review by public agency/organisation/private company & 3 \\
\hline DHB investigation & 3 \\
\hline Review by local authority & 15 \\
\hline Maritime New Zealand investigation & 12 \\
\hline Total & 3 \\
\hline
\end{tabular}


Chart 1. Link between type of recommendation and extent of implementation

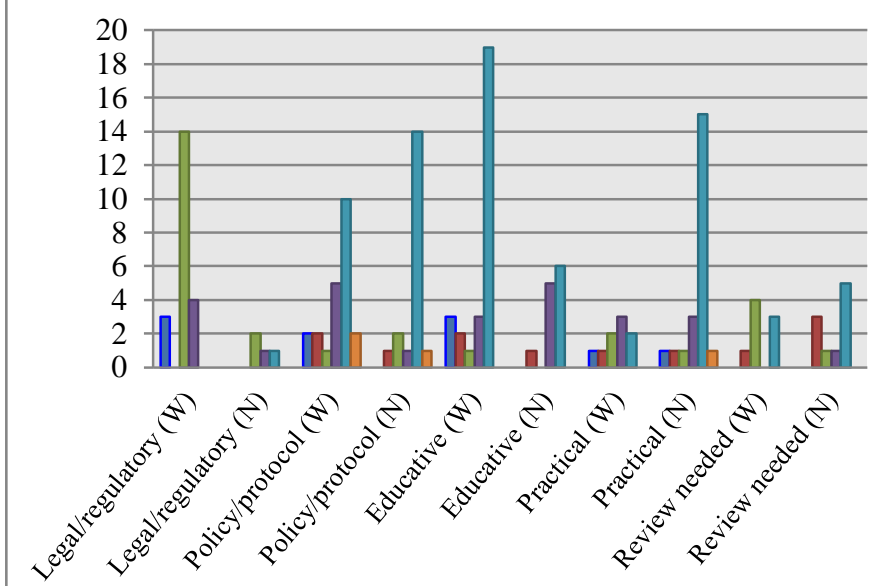

$\square$ Lost

$\square$ No response provided

$\square$ Not implemented

$\square$ Partial implementation

$\square$ Substantive implementation

$\square$ Changes made pre-inquiry

\section{Type of recommendation}

* $\mathrm{N}=$ Narrow $\quad \mathrm{W}=$ Wide 


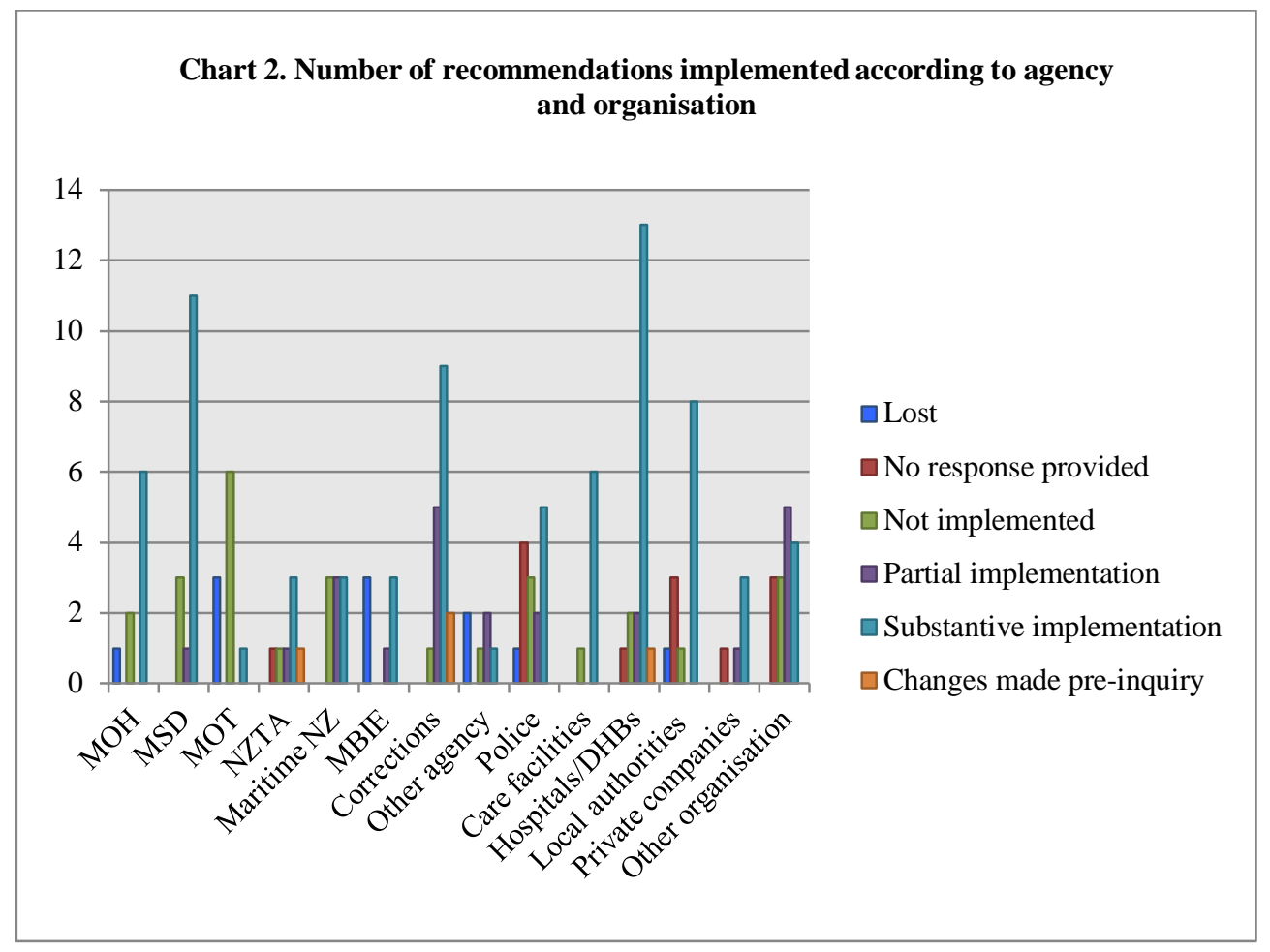

